Article

\title{
A New Geospatial Model Integrating a Fuzzy Rule-Based System in a GIS Platform to Partition a Complex Urban System in Homogeneous Urban Contexts
}

\author{
Barbara Cardone ${ }^{1}$ and Ferdinando Di Martino ${ }^{1,2, *(1)}$ \\ 1 Dipartimento di Architettura, Università degli Studi di Napoli Federico II, Via Toledo 402, 80134 Napoli, \\ Italy; b.cardone@unina.it \\ 2 Centro Interdipartimentale di Ricerca A. Calza Bini, Università degli Studi di Napoli Federico II, \\ Via Toledo 402, 80134 Napoli, Italy \\ * Correspondence: fdimarti@unina.it; Tel.: +39-081-552-253-8904
}

Received: 2 October 2018; Accepted: 21 November 2018; Published: 27 November 2018

\begin{abstract}
Here, we present a new unsupervised method aimed at obtaining a partition of a complex urban system in homogenous urban areas, called urban contexts. Our model integrates spatial analysis processes and a fuzzy rule-based system applied to manage the knowledge of domain experts; it is implemented using a GIS platform. The area of study is initially partitioned in microzones, homogeneous portions of the urban system, which are the atomic reference elements for the census data. With the contribution of domain experts, we identify the physical, morphological, environmental, and socio-economic indicators needed to identify synthetic characteristics of urban contexts and create the fuzzy rule set necessary for determining the type of urban context. We implement the set of spatial analysis processes required to calculate the indicators for the microzones and apply a Mamdani fuzzy rule system to classify the microzones. Finally, the partition of the area of study in urban contexts is obtained by dissolving continuous microzones belonging to the same type of urban context. Tests are performed on the Municipality of Pozzuoli (Naples, Italy); the reliability of the out model is measured by comparing the results with the ones obtained through a detailed analysis.
\end{abstract}

Keywords: urban system; urban context; microzone; fuzzy rule set; fuzzy system; GIS; spatial analysis; spatial database

\section{Introduction}

An urban system is a complex entity, composed of various elements with specific physical, morphological, environmental, and socio-economic characteristics. Often, in order to analyze an area of study related to urban analysis problems, it is useful to partition it into a set of homogeneous areas with respect to specific characteristics. In literature, there are various studies in which unsupervised methods are proposed to segment the area of study into homogeneous zones in order to analyze specific problems. Various authors propose automatic classification methods to partition urban areas and elements using raster remote sensing data. In Reference [1] a genetic algorithm is applied in order to automatically extract the classification rules of urban areas from remote sensing data. In Reference [2], a framework based on expert knowledge is applied in order to segment coastal areas using raster remote sensing data. In Reference [3], a new method based on unsupervised change detection focused on individual buildings is applied to very high-resolution remote sensing imagers to extract elements in urban systems. In Reference [4], a hierarchical object-oriented model is proposed to classify objects in 
an urban area from high-resolution satellite images. In Reference [5], a multiple-kernel learning model is proposed to classify urban areas from spectral and LiDAR raster data. A review of classification methods proposed to classify urban land cover through the use of raster LiDAR remote sensing images is presented in Reference [6].

Other recent studies propose decision-making spatial analysis models in which GIS and fuzzy systems are applied in engineering optimization analysis to solve decision-making problems, such as selection of the best logistic locations [7], the study of the prevention of a stroke [8], the optimization of green routes for city logistics centers [9], and the selection of the most suitable sites for wind-farm installments [10].

Recently, thanks to the availability of various thematic data at different scales from different institutional sources, together with the use of socio-demographic census data, it has been possible to implement methods for the unsupervised classification of urban systems that take into consideration knowledge of the urban system and expert knowledge of the problem being analyzed. In Reference [11], the area of study is partitioned into homogeneous zones based on morphological and soil characteristics in order to analyze the vulnerability of the aquifer to pollution; a fuzzy algebraic structure is applied to assess the aquifer vulnerability in any zone. In Reference [12], a multiple-level association rule mining method is applied to spatiotemporal socio-economic and land cover datasets based on a hierarchical classification scheme to extract relations between objects in the area of study and classify them.

In Reference [13], a simulated annealing method is applied to partition an area of study into homogeneous zones based on socio-economic characteristics. In Reference [14], a partition of the urban system in census zones is performed in order to study the spatial distribution of socio-economic characteristics. In Reference [15], a multi-objective approach is applied in order to partition the municipalities of the region of Parana in Brazil into microregions; this approach maximizes population homogeneity and the medical procedure used in any microregion and minimizes inter-microregion traveling.

In this study, we propose a novel model based on a Mamdani fuzzy rule-based system [16,17] aimed at partitioning an urban system into homogeneous zones, called urban contexts; each urban context is labeled with a specific urban class based on a specific taxonomy related to the problem being studied. Our goal is to model the knowledge and approximate reasoning of domain experts in order to apply them to partition the urban system.

Fuzzy logic plays a key role in approximate reasoning, and Fuzzy Logic Systems [18-20] are implemented to manage approximate knowledge in order to solve specific problems through the use of approximate reasoning. The Mamdani fuzzy rule-based model is the most well-known fuzzy logic system model; it has been successfully applied in many fields, such as automatic control [21], expert systems [22], mobile robots [23], and computer vision [24].

In References [25,26], approaches based on the Mamdani fuzzy rule-based system model for unsupervised classification are proposed. Our objective is to use a Mamdani fuzzy rule-based system to manage the experts' approximate reasoning applied to classify urban contexts.

Our approach is independent of the problem analyzed; initially, we partition the area of study into homogeneous zones provided by census atomic elements called microzones. We follow Italian Presidential Decree no. 138 of 1998, Article 1 (http://def.finanze.it/DocTribFrontend/ getAttoNormativoDetail.do?ACTION=getSommario\&id=`protect $\backslash \mathrm{T} 1 \backslash$ textbraceleftCE1306567850-4531-9B95-F17CC19790C4 \protect \T1 \textbraceright) of which defines a microzone as a homogeneous portion of the urban system, which may include one municipality, a portion thereof, or groups of municipalities, characterized by similar environmental and socio-economic characteristics. The microzone represents a portion of the municipality or, in the case of areas consisting of groups of municipalities, an entire municipal territory homogeneous in terms of its urban, historical-environmental, and socio-economic characteristics, as well as in the provision of urban services and infrastructure. For example, in each microzone, buildings are predominantly uniform in terms of their construction features, construction period, and residential/industrial/commercial use. 
The first step of our method concerns the acquisition of different, not normalized thematic data from various institutional sources, including from the last microzone census database.

Subsequently, a homogeneous knowledge base of the urban system analyzed is created, in order to extract a set of synthetic indicators representing the characteristics of the urban system related to the problem analyzed. These indicators express the input variables of a fuzzy rule set extracted by domain experts, in which the output variable expresses an urban class.

A Mamdani fuzzy rule system is applied to classify the microzones, assigning them a specific class; finally, a dissolve spatial operator is used to aggregate microzones that are spatially contiguous classified in the same urban class in urban contexts; in addition, we assess the membership degree of each urban context to its class, by using a weighted average of the membership degrees to this category calculated in any microzone included in the urban context. This membership degree represents the uncertainty of the attribution of the urban context to its urban class and provides an evaluation of the reliability of the classification.

The main advantages of the proposed model are its independence from the problem analyzed and its usability. In fact, our framework can be applied to any type of problem concerning the analysis of urban systems and streamlines and make the construction of knowledge transferred by domain experts more efficient. Finally, the assessment of the membership degree of the urban contexts to their urban classes allows the analyst to evaluate the reliability of the resultant partition.

In the next section, the proposed model is described in detail; in order to show the ways in which the components of our model are applied, a case study concerned with partitioning an urban system in the contexts in which urban classes are typified according to different residential densities is explored.

In Section 3, the area of study and the institutional datasets used in our experiments are described; Section 4 presents the results of our experiments; and some final considerations are reported in Section 5.

\section{The Proposed Model}

Our model is composed of a set of five phases, as shown in Figure 1.

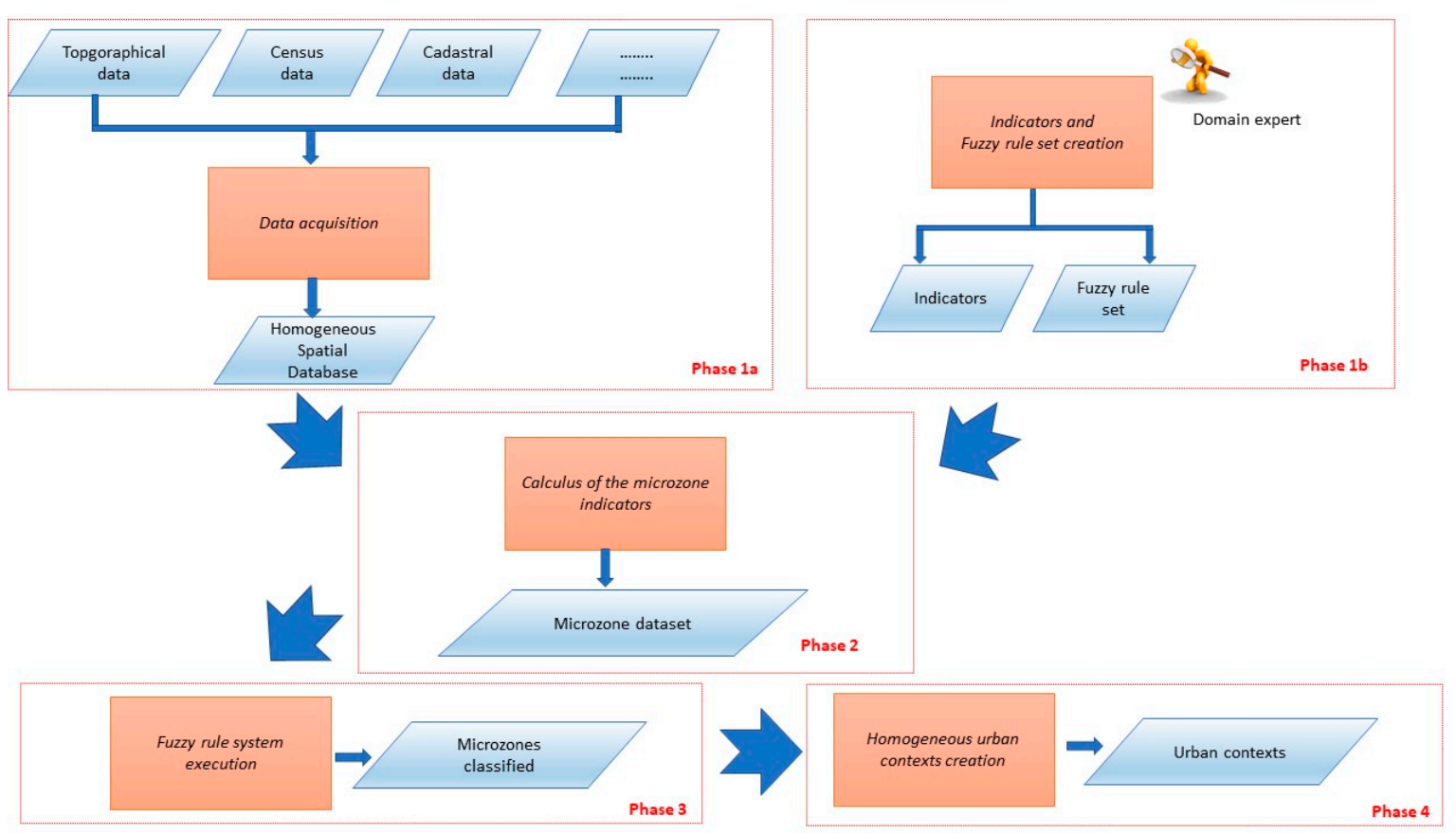

Figure 1. Scheme of the phases of the model. 
Phases $1 \mathrm{a}$ and $1 \mathrm{~b}$ are executable in parallel.

Phase 1a (Data acquisition) concerns the acquisition of the datasets from institutional sources. A set of staging procedures are required to allow for the reconciliation of these inhomogeneous data (for example, to carry out the transformation and conversions of spatial data in a unique coordinate system and to correct spatial topological errors) and the creations of relations between the various datasets. The output of this phase is given by the homogeneous spatial database of the area of study.

In phase $1 \mathrm{~b}$ (Indicators and fuzzy rule set creation) the various physical, environmental, and socio-economic indicators are defined and the fuzzy rule set is created; this phase is executed with the contribution of domain experts. To model the expert knowledge and construct the fuzzy rules, we created a fuzzy partition of the domain of each indicator in which any fuzzy set is assigned by using a triangular or semi-trapezoidal fuzzy number and is titled with a linguistic label assigned by the domain expert.

In phase 2 (Calculus of the microzone indicators), the spatial analysis processes need to calculate the indicators are implemented. Each indicator represents a summary of the specific characteristics of the microzone; it is calculated by applying the formulas created in phase $1 \mathrm{~b}$ and by using a set of geoprocessing and statistical operators applied to entities and characteristics in the spatial database.

In phase 3 (Fuzzy rule system execution) for each microzone the Mamdani fuzzy rule system is executed in order to assign the microzone to a specific urban class. The indicators are fuzzified using a fuzzification component; then, the fuzzy inference component is applied by using the Mamdani min and max operators; and the urban class assigned to the microzone is given by the consequent of the fuzzy rule with the greatest strength.

In phase 4 (Homogeneous urban contexts creation), the adjoining microzones belonging to the same urban class are dissolved and the thematic map of the urban contexts of the area of study is created.

\subsection{Phase $1 a-D a t a$ Acquisition}

In this phase, data concerning the area of study are acquired from various institutional sources. The output of this phase is a spatial database implementing the homogenous knowledge base of the area of study. A spatial dataset is provided by the microzone census data, including the polygon spatial data corresponding to the microzones. Other datasets are needed to extract the synthetic indicators related to different information layers, such as population, buildings, roads, urban green, schools, and infrastructures.

A set of geoprocessing activities are required in order to normalize the spatial datasets; all the datasets must be converted using a unique coordinate system and a topological check is necessary to verify the integrity of the dataset. Other geoprocessing activities could be carried out to extract and normalize the thematic data, such as:

- $\quad$ Extracting themes from a dataset in various formats;

- Merging datasets corresponding to a theme and distributed per tiles, clipped onto the area of study;

- Applying spatial operators related to any feature of the theme information, inserted as annotation texts (for example, the road name assigned to any polyline of a road network).

A data cleaning activity on the data fields it required in order to verify their integrity and accuracy, to delete outliers, and to correct inconsistent data and redundancies.

Finally, all the themes and tables are imported in a spatial database and the relation between them is established. 


\subsection{Phase $1 b$-Indicators and Fuzzy Rule Set Creation}

The indicators needed to classify the microzones are evaluated by domain experts. In our experiment, the experts consider 14 indicators related to various thematic layers that characterize the areas of study and which are needed to evaluate to which urban class the microzone belongs. In Table 1, all the indicators are described; each indicator is assigned an identify and the type of indicator is reported, i.e., the thematic layer to which it refers, a brief description, and the unit of measurement.

Table 1. Indicators used to classify the microzones of the area of study.

\begin{tabular}{cclc}
\hline Indicator & Type & \multicolumn{1}{c}{ Description } & Unit of Measurement \\
\hline $\mathrm{I}_{2}$ & Buildings & Mean square meters of residential buildings per resident & Square meters \\
\hline $\mathrm{I}_{3}$ & Urban green & Mean square meters of green areas per resident & Percent \\
\hline $\mathrm{I}_{4}$ & Urban green & Percent of green areas with respect to area of the microzone & Percent \\
\hline $\mathrm{I}_{5}$ & Roads & $\begin{array}{l}\text { Percent of the overall length of district urban roads }{ }^{1} \text { with } \\
\text { respect to the overall length of roads in the microzone }\end{array}$ & Percent \\
\hline $\mathrm{I}_{6}$ & Roads & $\begin{array}{l}\text { Percent of overall length of the district urban roads with a } \\
\text { width of less than 7 m with respect to the overall length of all } \\
\text { the district urban roads in the microzone }\end{array}$ & Percent \\
\hline $\mathrm{I}_{7}$ & Population & Number of residents per square kilometer & Percent \\
\hline $\mathrm{I}_{8}$ & Buildings & $\begin{array}{l}\text { Percent of the number of residential buildings built before } \\
\text { 1945 with respect to all residential buildings }\end{array}$ & (Square kilometers) \\
\hline $\mathrm{I}_{9}$ & buildings & $\begin{array}{l}\text { Mean number of dwellings with at least one resident in the } \\
\text { residential buildings }\end{array}$ & Percent \\
\hline $\mathrm{I}_{10}$ & Buildings & $\begin{array}{l}\text { Percent of residential buildings with at least 16 dwellings with } \\
\text { respect to all residential buildings }\end{array}$ & Percent \\
\hline $\mathrm{I}_{11}$ & Schools & Accessibility and proximity of schools in the microzone & Percent \\
\hline $\mathrm{I}_{12}$ & Public transportation & Usability of public transport networks & Percent \\
\hline $\mathrm{I}_{13}$ & Coastal/marine zone & Coastal/marine area & Percent \\
\hline $\mathrm{I}_{14}$ & $\begin{array}{l}\text { Large public } \\
\text { infrastructure }\end{array}$ & \begin{tabular}{l} 
Presence of large public infrastructures \\
\hline
\end{tabular} & \begin{tabular}{l} 
1 Urban district road: single carriageway with at least two lanes, paved quays, and sidewalks. \\
\hline
\end{tabular}
\end{tabular}

After defining the indicators, the domain experts create a fuzzy partition of each indicator by using triangular and semi-trapezoidal fuzzy numbers to create the fuzzy sets. The fuzzy partitions of the indicators in Table 1 are shown in Table 2, in which the identifier of the indicator, a label assigned to the fuzzy sets, the inf, mean and sup values of the fuzzy number and the type of fuzzy set (ST $=$ Semi-Trapezoidal, $\mathrm{TR}=$ Triangular $)$ are reported .

In order to extract the fuzzy rules, the experts define the taxonomy of the urban area classes. In our experiment, the following set of urban area classes is considered, in which each class characterizes a type of residential or rural zone of the urban system.

Each class in Table 3 corresponds to a fuzzy set of output linguistic variable $\mathrm{Z}$ defined in the domain $[0,1]$ and, following an increasing order from 0 to 1 , represents the impact of residential settlements on the area. The first fuzzy set is a semi-trapezoidal fuzzy set representing a predominantly rural or wooded area; the last fuzzy set is a semi-trapezoidal fuzzy set representing a compact residential old town. The intermediate fuzzy sets are triangular. These fuzzy sets are defined in Table 4 and are graphically presented in Figure 2. 
Table 2. Fuzzy partitions of the indicators $(\mathrm{ST}=$ Semi-Trapezoidal, $\mathrm{TR}=$ Triangular $)$.

\begin{tabular}{|c|c|c|c|c|c|}
\hline Indicator & Label & Inf & Mean & Sup & Type of Fuzzy Set \\
\hline \multirow{4}{*}{$\mathrm{I}_{1}$} & Scanty & 0 & 10 & 30 & ST \\
\hline & Mean & 20 & 30 & 50 & TR \\
\hline & Discrete & 40 & 60 & 80 & TR \\
\hline & High & 70 & 100 & $\infty$ & ST \\
\hline \multirow{4}{*}{$\mathrm{I}_{2}$} & Null & 0 & 10 & 20 & ST \\
\hline & Mean & 10 & 30 & 50 & TR \\
\hline & Discrete & 40 & 50 & 70 & TR \\
\hline & High & 60 & 70 & 100 & ST \\
\hline \multirow{4}{*}{$\mathrm{I}_{3}$} & Scanty & 0 & 10 & 40 & ST \\
\hline & Mean & 30 & 50 & 70 & TR \\
\hline & Discrete & 60 & 80 & 90 & TR \\
\hline & High & 90 & 200 & $\infty$ & ST \\
\hline \multirow{4}{*}{$\mathrm{I}_{4}$} & Null & 0 & 10 & 30 & ST \\
\hline & Mean & 10 & 30 & 50 & TR \\
\hline & Discrete & 30 & 50 & 70 & TR \\
\hline & High & 50 & 70 & 100 & ST \\
\hline \multirow{4}{*}{$\mathrm{I}_{5}$} & Null & 0 & 20 & 30 & ST \\
\hline & Mean & 15 & 40 & 50 & TR \\
\hline & Discrete & 40 & 50 & 70 & $\mathrm{TR}$ \\
\hline & High & 60 & 70 & 100 & $\mathrm{ST}$ \\
\hline \multirow{4}{*}{$\mathrm{I}_{6}$} & Null & 0 & 10 & 20 & ST \\
\hline & Mean & 10 & 30 & 50 & TR \\
\hline & Discrete & 40 & 50 & 70 & $\mathrm{TR}$ \\
\hline & High & 60 & 70 & 100 & $\mathrm{ST}$ \\
\hline \multirow{4}{*}{$\mathrm{I}_{7}$} & Scanty & 0 & 100 & 1000 & ST \\
\hline & Mean & 100 & 1000 & 5000 & TR \\
\hline & Discrete & 1000 & 5000 & 10000 & TR \\
\hline & High & 5000 & 10000 & $\infty$ & ST \\
\hline \multirow{4}{*}{$\mathrm{I}_{8}$} & Null & 0 & 10 & 20 & ST \\
\hline & Mean & 10 & 30 & 50 & $\mathrm{TR}$ \\
\hline & Discrete & 40 & 50 & 70 & $\mathrm{TR}$ \\
\hline & High & 60 & 80 & 100 & $\mathrm{ST}$ \\
\hline \multirow{4}{*}{$\mathrm{I}_{9}$} & Scanty & 0 & 5 & 10 & ST \\
\hline & Mean & 5 & 20 & 30 & TR \\
\hline & Discrete & 30 & 40 & 60 & TR \\
\hline & High & 40 & 60 & $\infty$ & ST \\
\hline \multirow{4}{*}{$\mathrm{I}_{10}$} & Null & 0 & 10 & 20 & ST \\
\hline & Mean & 10 & 30 & 50 & TR \\
\hline & Discrete & 40 & 60 & 80 & TR \\
\hline & High & 60 & 80 & 100 & ST \\
\hline \multirow{4}{*}{$\mathrm{I}_{11}$} & Null & 0 & 10 & 20 & ST \\
\hline & Mean & 10 & 30 & 50 & TR \\
\hline & Discrete & 50 & 70 & 90 & TR \\
\hline & High & 70 & 90 & 100 & ST \\
\hline \multirow{4}{*}{$\mathrm{I}_{12}$} & Null & 0 & 10 & 20 & ST \\
\hline & Mean & 10 & 30 & 50 & TR \\
\hline & Discrete & 40 & 50 & 70 & TR \\
\hline & High & 60 & 70 & 100 & ST \\
\hline \multirow{3}{*}{$\mathrm{I}_{13}$} & Null & 0 & 10 & 30 & ST \\
\hline & Mean & 30 & 50 & 70 & TR \\
\hline & High & 60 & 90 & 100 & $\mathrm{ST}$ \\
\hline \multirow{4}{*}{$\mathrm{I}_{14}$} & Null & 0 & 10 & 20 & ST \\
\hline & Mean & 10 & 50 & 70 & TR \\
\hline & Discrete & 50 & 80 & 90 & TR \\
\hline & High & 60 & 90 & 100 & ST \\
\hline
\end{tabular}


Table 3. Urban area classes.

\begin{tabular}{ll}
\hline \multicolumn{1}{c}{ Urban area class } & \multicolumn{1}{c}{ Description } \\
\hline Residential old town & $\begin{array}{l}\text { Residential agglomeration of ancient or recent formation characterized by } \\
\text { historical, artistic, and environmental goods even if tampered with or degraded } \\
\text { or not present at the same time }\end{array}$ \\
\hline Comfortable residential zone & $\begin{array}{l}\text { Dwelling place equipped with comfortable and modern/contemporary } \\
\text { dwellings, infrastructures, sports facilities, and green spaces }\end{array}$ \\
\hline Downtrodden residential zone & $\begin{array}{l}\text { Dwelling place equipped with uncomfortable dwellings and lacking } \\
\text { infrastructures, sports facilities, and green spaces }\end{array}$ \\
\hline Industrial zone & Zone with prevalent or mixed industrial areas \\
\hline Coastal residential zone & Area inclusive of a border with sea or great lakes with mainly maritime services \\
\hline Fragmented rural/wooded zone & Mainly rural or wooded area with reduced settlement development \\
\hline Sprawl & Informal modern/contemporary urban settlement \\
\hline
\end{tabular}

Table 4. Fuzzy partitions of the urban area classes.

\begin{tabular}{ccccc}
\hline Urban Area Class & Inf & Mean & Sup & Type of Fuzzy Set \\
\hline Fragmented rural/wooded zone & 0 & 0.2 & 0.3 & ST \\
Industrial zone & 0.2 & 0.3 & 0.4 & TR \\
Sprawl & 0.3 & 0.4 & 0.5 & TR \\
Coastal residential zone & 0.4 & 0.5 & 0.6 & TR \\
Comfortable residential zone & 0.5 & 0.6 & 0.7 & TR \\
Downtrodden residential zone & 0.6 & 0.7 & 0.8 & TR \\
Residential old town & 0.7 & 0.8 & 1 & ST \\
\hline
\end{tabular}

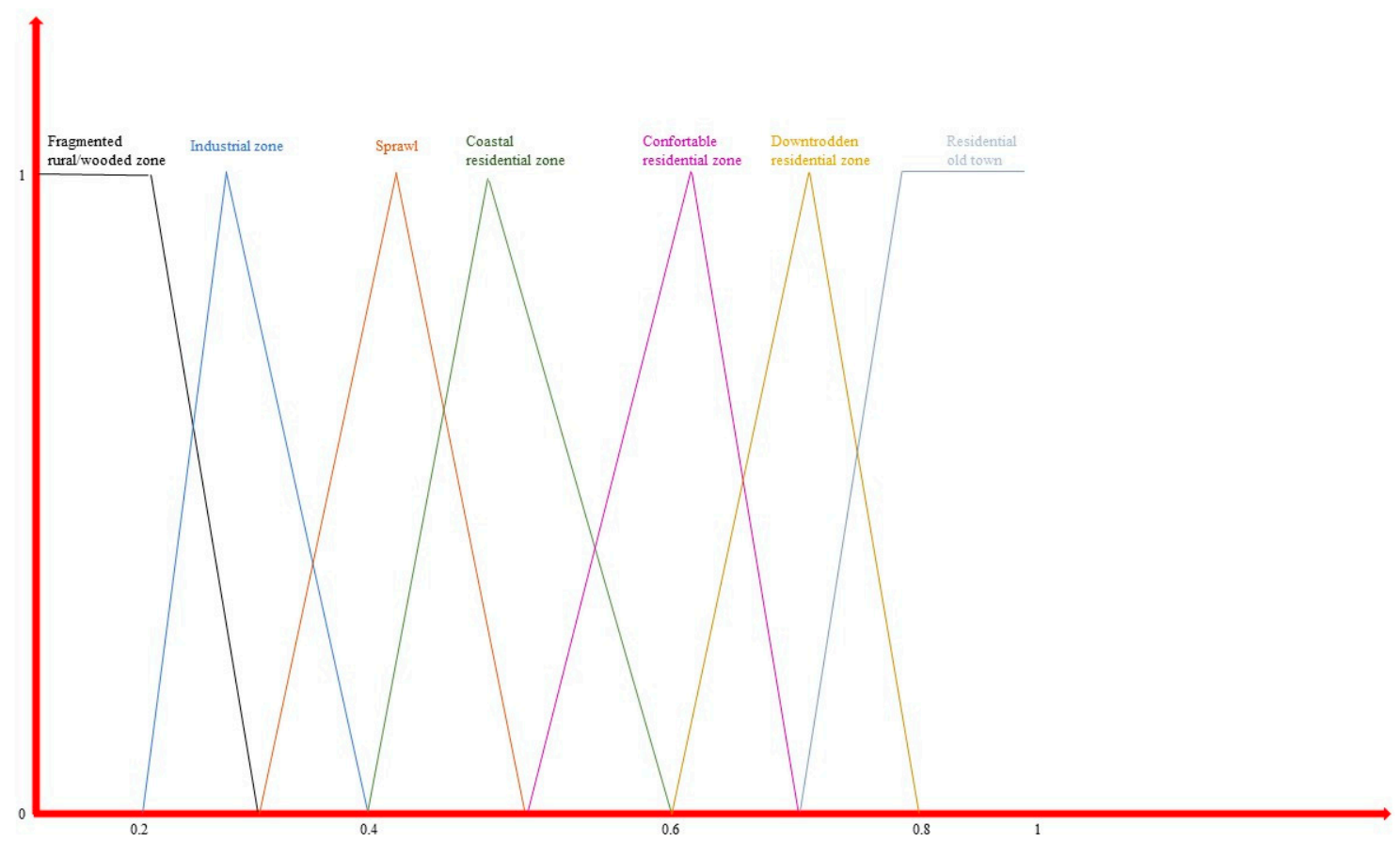

Figure 2. Plotting of the output variable fuzzy sets.

Based on their knowledge, the experts extract the set of fuzzy rules needed to evaluate the urban class to which each microzone belongs. In our experiment, the 14 indicators are used as input variables in the antecedent of each rule and output variable $\mathrm{Z}$ is used in the consequent, labeled as presented 
in Table 3. The fuzzy rule set is composed of fuzzy rules extracted by the experts, written in the following form:

$$
\mathrm{R}_{\mathrm{k}}: \operatorname{IF}\left(\mathrm{I}_{1}=\mathrm{I}_{1 \mathrm{k}}\right) \Delta_{1}\left(\mathrm{I}_{2}=\mathrm{I}_{\mathrm{k}}\right) \Delta_{2} \ldots \Delta_{\mathrm{n}}\left(\mathrm{I}_{\mathrm{n}}=\mathrm{I}_{\mathrm{nk}}\right) \operatorname{THEN}\left(\mathrm{Z}=\mathrm{Z}_{\mathrm{k}}\right)
$$

where $I_{1}, I_{2}, I_{n}$, are the input variables given by the linguistic labels of the fuzzy sets of the indicators and $\mathrm{Z}$ is the output variable. The operator $\Delta_{\mathrm{i}}(\mathrm{i}=1, \ldots, \mathrm{n})$ is given by an AND or an OR connective. We construct the fuzzy rule set considering only AND connectives, splitting rules in which there are OR connectives in the antecedent. To show the splitting process of the rules, we take into consideration the following subset of fuzzy rules created by the experts:

IF $\left(\mathrm{I}_{4}==\right.$ Null $)$ AND $\left(\mathrm{I}_{6}==\right.$ Discrete $\mathrm{OR} \mathrm{I}_{6}==$ High $)$ AND $\left(\mathrm{I}_{7}==\right.$ High $)$ THEN Z == Residential old town IF $\left(\mathrm{I}_{1}==\right.$ Discrete OR $\mathrm{I}_{1}==$ High $)$ AND $\left(\mathrm{I}_{3}==\right.$ Discrete $\mathrm{OR} \mathrm{I}_{3}==$ High $)$ AND $\left(\mathrm{I}_{8}==\right.$ Null $)$ AND $\left(\mathrm{I}_{12}==H i g h\right)$ THEN $\mathrm{Z}==$ Comfortable residential zone

IF $\left(\mathrm{I}_{2}==\right.$ Null $)$ AND $\left(\mathrm{I}_{7}==\right.$ Scanty OR $\mathrm{I}_{7}==$ Mean $)$ AND $\left(\mathrm{I}_{12}==\right.$ High $)$ AND $\left(\mathrm{I}_{14}==\right.$ Discrete OR $\mathrm{I}_{14}==$ High) THEN $\mathrm{Z}==$ Comfortable residential zone

IF $\left(\mathrm{I}_{2}==\right.$ Discrete OR $\mathrm{I}_{2}==$ High $)$ AND $\left(\mathrm{I}_{6}==\right.$ Null $)$ AND $\left(\mathrm{I}_{7}==\right.$ Scanty $)$ THEN $\mathrm{Z}==$ Industrial zone

After the rule-splitting process, we obtain the following final fuzzy rules:

$\mathbf{R}_{\mathbf{1}}$ : IF $\left(\mathrm{I}_{4}==\right.$ Null $)$ AND $\left(\mathrm{I}_{6}==\right.$ Discrete OR $\mathrm{I}_{6}==$ High) AND $\left(\mathrm{I}_{7}==\right.$ High $)$ THEN Z == Residential old town

$\mathbf{R}_{2}$ : IF $\left(\mathrm{I}_{4}==\right.$ Null $)$ AND $\left(\mathrm{I}_{6}==H i g h\right)$ AND $\left(\mathrm{I}_{7}==\right.$ High) THEN Z == Residential old town

$\mathbf{R}_{3}$ : IF $\left(\mathrm{I}_{1}==\right.$ Discrete $)$ AND $\left(\mathrm{I}_{3}==\right.$ Discrete $)$ AND $\left(\mathrm{I}_{8}==\right.$ Null $)$ AND $\left(\mathrm{I}_{12}==\right.$ High $)$ THEN Z == Comfortable residential zone

$\mathbf{R}_{4}$ : IF $\left(\mathrm{I}_{1}==\right.$ High $)$ AND $\left(\mathrm{I}_{3}==\right.$ Discrete $)$ AND $\left(\mathrm{I}_{8}==\right.$ Null $)$ AND $\left(\mathrm{I}_{12}==\right.$ High $)$ THEN Z == Comfortable residential zone

$\mathbf{R}_{\mathbf{5}}$ : IF ( $\mathrm{I}_{1}==$ Discrete) $\mathrm{AND}\left(\mathrm{I}_{3}==\right.$ High $)$ AND $\left(\mathrm{I}_{8}==\right.$ Null $)$ AND $\left(\mathrm{I}_{12}==\right.$ High $)$ THEN Z == Comfortable residential zone

$\mathbf{R}_{6}$ : IF $\left(\mathrm{I}_{1}==\right.$ High $)$ AND $\left(\mathrm{I}_{3}==\right.$ High $)$ AND $\left(\mathrm{I}_{8}==\right.$ Null $)$ AND $\left(\mathrm{I}_{12}==\right.$ High) THEN Z == Comfortable residential zone

$\mathbf{R}_{\mathbf{7}}$ : IF $\left(\mathrm{I}_{2}==\right.$ Null $)$ AND $\left(\mathrm{I}_{7}==\right.$ Scanty $)$ AND $\left(\mathrm{I}_{12}==\right.$ High $)$ AND $\left(\mathrm{I}_{14}==\right.$ Discrete $)$ THEN Z == Comfortable residential zone

$\mathbf{R}_{\mathbf{8}}$ : IF $\left(\mathrm{I}_{2}==\right.$ Null $)$ AND $\left(\mathrm{I}_{7}==\right.$ Mean $)$ AND $\left(\mathrm{I}_{12}==\right.$ High $)$ AND $\left(\mathrm{I}_{14}==\right.$ Discrete $)$ THEN Z == Comfortable residential zone

R9: IF ( $\mathrm{I}_{2}==$ Null) AND ( $\mathrm{I}_{7}==$ Scanty) AND $\left(\mathrm{I}_{12}==\right.$ High $)$ AND $\left(\mathrm{I}_{14}==\right.$ High $)$ THEN Z == Comfortable residential zone

$\mathbf{R}_{10}$ : IF $\left(\mathrm{I}_{2}==\right.$ Null $)$ AND $\left(\mathrm{I}_{7}==\right.$ Mean $)$ AND $\left(\mathrm{I}_{12}==\right.$ High $)$ AND $\left(\mathrm{I}_{14}==\right.$ High $)$ THEN Z == Comfortable residential zone

$\mathbf{R}_{11}$ : IF ( $\mathrm{I}_{2}==$ Discrete) AND ( $\mathrm{I}_{6}==$ Null) AND $\left(\mathrm{I}_{7}==\right.$ Scanty) THEN Z == Industrial zone

$\mathbf{R}_{\mathbf{1 2}}$ : IF ( $\mathrm{I}_{2}==$ High $)$ AND $\left(\mathrm{I}_{6}==\right.$ Null $)$ AND $\left(\mathrm{I}_{7}==\right.$ Scanty $)$ THEN $\mathrm{Z}==$ Industrial zone

\subsection{Phase 2-Calculus of the Microzone Indicators}

To calculate the indicators in each microzone, specific spatial analysis functions are applied. For example, the indicator $I_{1}$ in Table 1 is calculated by selecting the residential buildings in the area of study and extracting the total surface area covered by residential buildings and the number of residents per microzone. Finally, for each microzone, the ratio between this total surface area and the number of residents is calculated.

A hierarchy of spatial analysis processes could be needed in order to calculate the value of an indicator. In our experiment, to calculate the indicators $\mathrm{I}_{11}, \mathrm{I}_{12}, \mathrm{I}_{13}$ and $\mathrm{I}_{14}$, is necessary to calculate further parameters, labeled as II level indicators, described in Table 5. 
Table 5. II level indicators used to classify the microzones of the area of study.

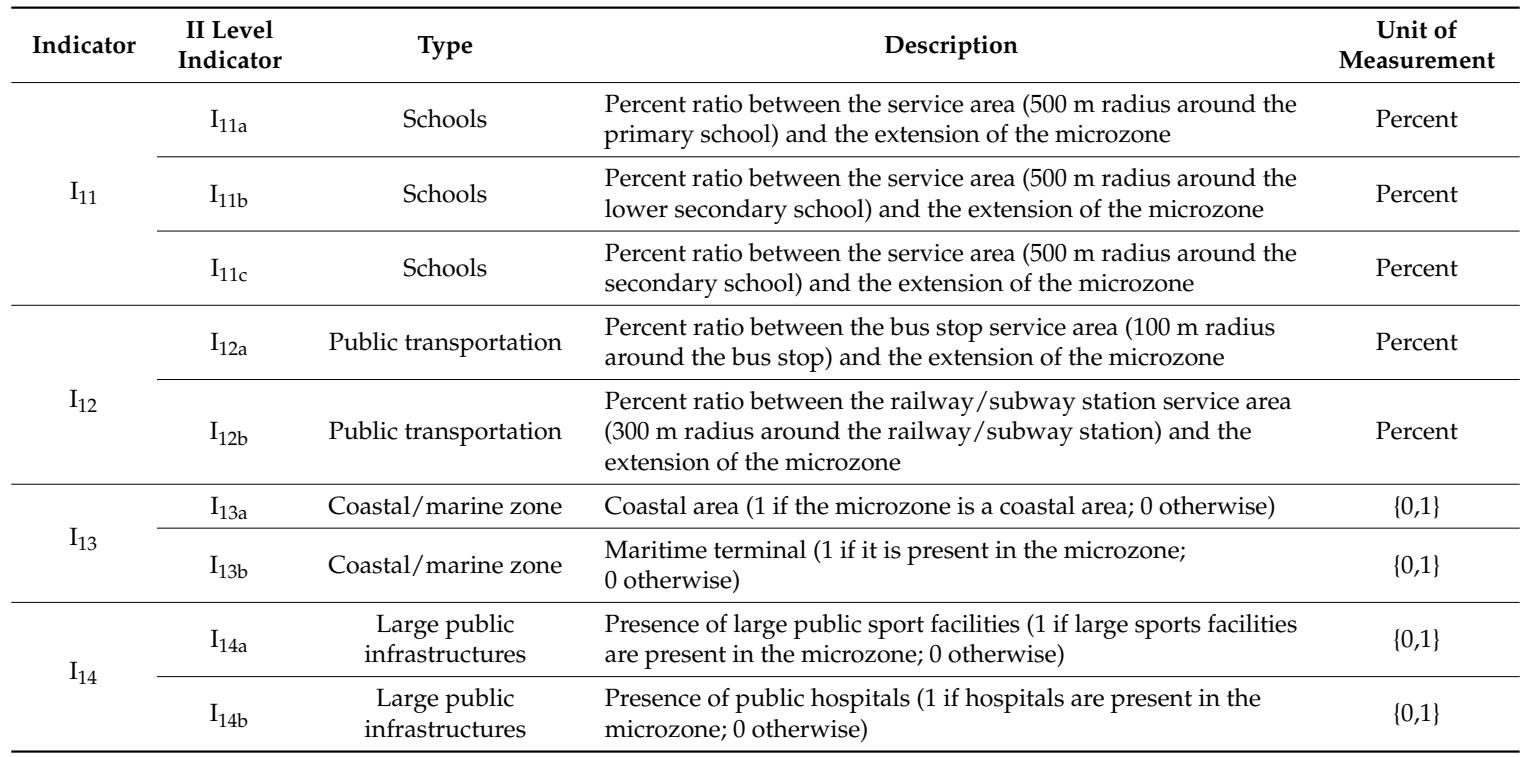

The indicator $\mathrm{I}_{11}$ is obtained as a weighted mean of the indicators $\mathrm{I}_{11 a}, \mathrm{I}_{11 b}$ and $\mathrm{I}_{11 b}$, where the weights are, respectively, residents aged between 5 and 9 years, residents aged between 10 and 14 years, and residents aged between 15 and 19 years.

Formally, let $\mathrm{n}_{5-9}$ be the number of residents in the microzone with an age in the range of 5-9 years, let $\mathrm{n}_{10-14}$ be the number of residents in the microzone with an age in the range of 10-14 years, and let $\mathrm{n}_{15-19}$ be the number of residents in the microzone with an age in the range of 15-19 years.

The indicator $\mathrm{I}_{11}$ is given by the formula:

$$
\mathrm{I}_{11}=\frac{\mathrm{I}_{11 \mathrm{a}} \times \mathrm{n}_{5-9}+\mathrm{I}_{11 \mathrm{~b}} \times \mathrm{n}_{10-14}+\mathrm{I}_{11 \mathrm{c}} \times \mathrm{n}_{15-19}}{\mathrm{n}_{5-9}+\mathrm{n}_{10-14}+\mathrm{n}_{15-19}}
$$

The indicator $\mathrm{I}_{12}$ is obtained as a weighted mean of the indicators $\mathrm{I}_{12 \mathrm{a}}$ and $\mathrm{I}_{12 \mathrm{~b}}$.

$$
I_{12}=\frac{I_{12 a} \times w_{12 a}+I_{12 b} \times w_{12 b}}{w_{12 a}+w_{12 b}}
$$

where $\mathrm{w}_{12 \mathrm{a}}$ and $\mathrm{w}_{12 \mathrm{~b}}$ are the weights assigned, respectively, to the indicators $\mathrm{I}_{11 \mathrm{a}}$ and $\mathrm{I}_{11 \mathrm{~b}}$. The experts set $w_{12 a}=3$ and $w_{12 b}=7$, considering the influence of railway/subway station services to be greater than that of bus services.

The indicator $\mathrm{I}_{13}$ is calculated as:

$$
\mathrm{I}_{13}= \begin{cases}0 \% & \text { IF I }_{13 \mathrm{a}}=0 \\ 50 \% & \text { IF I }_{13 \mathrm{a}}=1 \text { AND I } \\ 13 \mathrm{~b}=0 \\ 100 \% & \text { IF I I }_{13 \mathrm{a}}=1 \text { AND I I } 13 \mathrm{~b}=1\end{cases}
$$

The indicator $\mathrm{I}_{14}$ is calculated as:

$$
\mathrm{I}_{14}= \begin{cases}0 \% & \text { IF I I }_{14 \mathrm{a}}=0 \text { AND I }_{14 \mathrm{~b}}=0 \\ 50 \% & \text { IF I }_{14 \mathrm{a}}=1 \text { AND I I }_{14 \mathrm{~b}}=0 \\ 80 \% & \text { IF I I }_{14 \mathrm{a}}=0 \text { AND I }_{14 \mathrm{~b}}=1 \\ 100 \% & \text { IF I I }_{14 \mathrm{a}}=1 \text { AND I } \\ 14 \mathrm{~b} & =1\end{cases}
$$




\subsection{Phase 3-Fuzzy Rule System Execution}

In this phase, a Mamdani fuzzy rule-based system is used to classify the microzones. In Figure 3, the fuzzy rule-based system used is schematized.

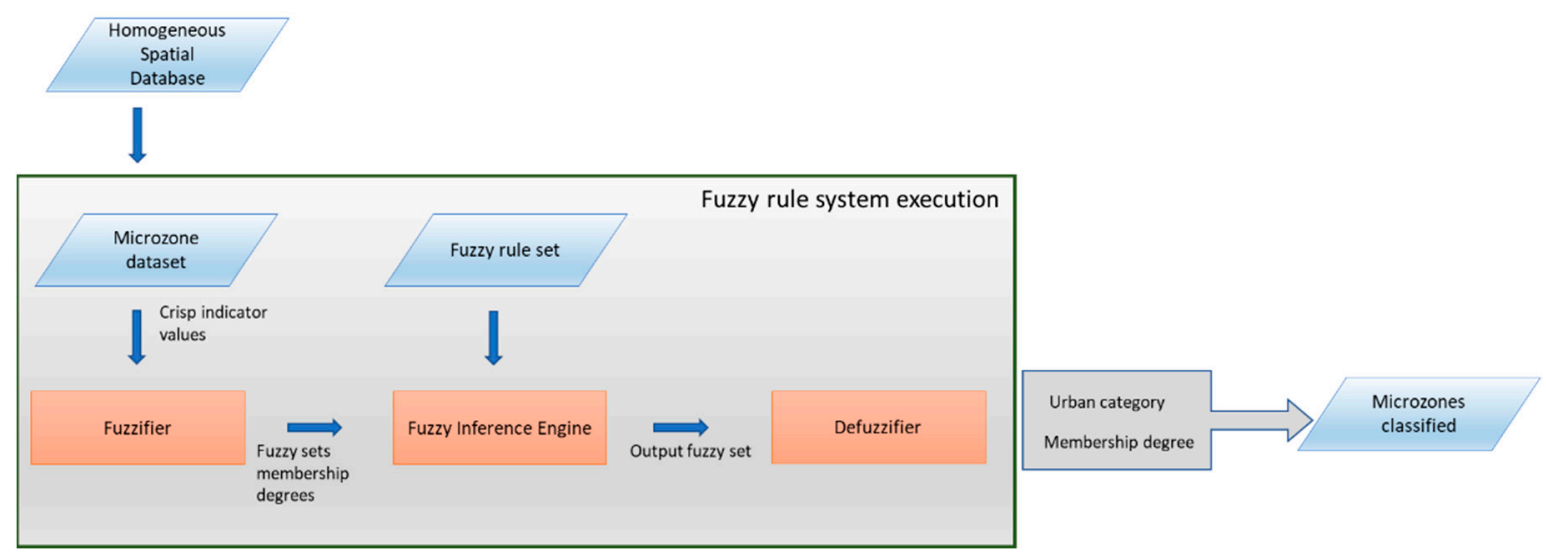

Figure 3. Scheme of the fuzzy rule-based system.

From the spatial database constructed in the previous phase, the microzone dataset containing the crisp values of the indicators calculated for each microzone is extracted. The Fuzzifier component imports these indicator values and assigns each indicator the membership degree to its fuzzy sets. Then, the Fuzzy Inference Engine component reads the membership degree of the fuzzy sets related to each indicator and performs the inference process by calculating the strength of each fuzzy rule in the fuzzy rule set.

The min operator is applied to the AND connectives in the antecedent of the fuzzy rule to calculate its strength. The Fuzzy Inference Engine carries out the aggregation process to construct the output final fuzzy set. Aggregation is the process by which the truncated output fuzzy sets in each rule are combined into a single fuzzy set that represents the output aggregated fuzzy set.

In order to show the aggregation process, we consider a system formed of two fuzzy rules in the form:

$$
\begin{cases}R_{1}: & \text { IF }\left(I_{1} \text { is } A_{1}\right) \text { AND }\left(I_{2} \text { is } B_{1}\right) \text { THEN Z is } C_{1} \\ R_{2}: & \text { IF }\left(I_{1} \text { is } A_{2}\right) \text { AND }\left(I_{2} \text { is } B_{2}\right) \text { THENZ is } C_{2}\end{cases}
$$

where $A_{1}$ and $A_{2}$ are two fuzzy sets of the linguistic input variable $I_{1}, B_{1}$ and $B_{2}$ are two fuzzy sets of the input linguistic variable $I_{2}$, and $C_{1}$ and $C_{2}$ are two fuzzy sets of the output variable $Z$.

Now let us suppose that, after the fuzzification process, we obtain the following membership degree for the input variables: $\mathrm{A}_{1}=0.3, \mathrm{~B}_{1}=0.5, \mathrm{~A}_{2}=0.7, \mathrm{~B}_{1}=0.8$.

The strengths of the two rules are given by:

$$
\mathrm{S}\left(\mathrm{R}_{1}\right)=\min (0.3,0.5)=0.3 \quad \mathrm{~S}\left(\mathrm{R}_{2}\right)=\min (0.7,0.8)=0.7 .
$$

In the aggregation process, we construct the output fuzzy set given by:

$$
\mathrm{C}(\mathrm{Z})=\max \left\{\min \left[\mathrm{C}_{1}(\mathrm{Z}), \mathrm{S}\left(\mathrm{R}_{1}\right)\right], \min \left[\mathrm{C}_{2}(\mathrm{Z}), \mathrm{S}\left(\mathrm{R}_{2}\right)\right]\right\}
$$

In Figure 4, the output fuzzy set constructed in this example is presented. 


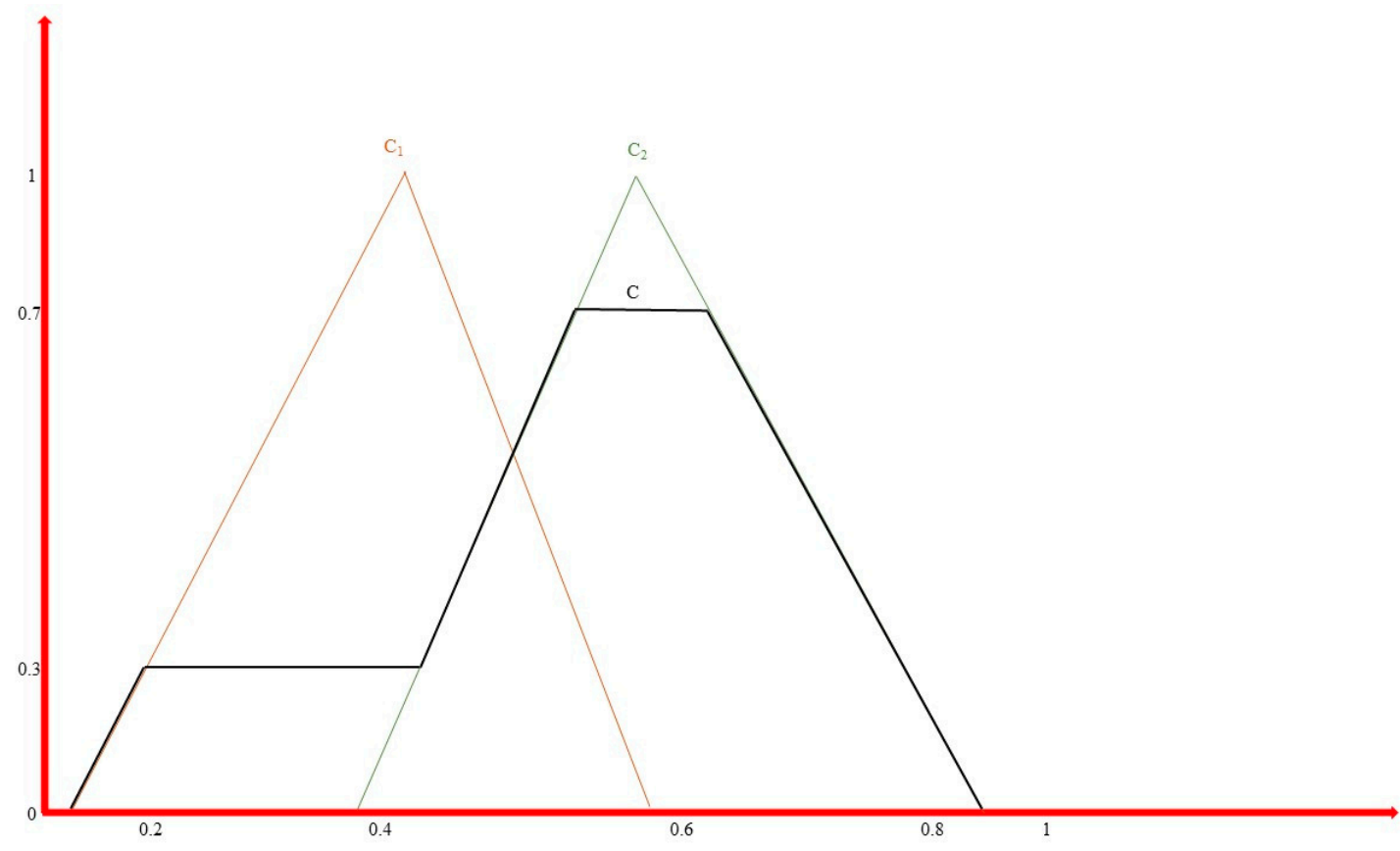

Figure 4. Example of construction of the output fuzzy set in the aggregation process.

The defuzzification process of the output fuzzy set is carried out using the discrete Center of Gravity (CoG) method, with the following formula:

$$
\hat{Z}=\frac{\int_{0}^{1} \mathbf{Z} \times \mathbf{C}(\mathbf{Z}) d \mathbf{Z}}{\int_{0}^{1} \mathrm{C}(\mathrm{Z}) d \mathrm{Z}}
$$

where the two integrals are extended in the range [0,1], which is the domain of the output variable $Z$.

We classify the microzone by assigning it to urban class label of the output variable fuzzy set with a greater membership degree in the point $\hat{Z}$; the degree of membership of the microzone to this class is given by the degree of membership of the output variable to $C$ in the point $\hat{Z}$.

In Figure 5 , the results of the defuzzification process are shown. As $C_{1}(\hat{Z})$ is greater than $C_{2}(\hat{Z})$, we assign the microzone to class $C_{1}$ with a membership degree given by $C(\hat{Z})$.

The Center of Gravity $\hat{Z}$ can be easily calculated considering $N$ discrete points of $C(Z)$ and discretizing the formula (7), obtaining:

$$
\hat{Z}=\frac{\sum_{i=1}^{N} Z_{i} \times C\left(Z_{i}\right)}{\sum_{i=1}^{N} Z_{i}}
$$

In Figure 5, we consider six points corresponding to the boundaries of the segments of the broken line $Z$, obtaining using the formula (9) $\hat{Z}=0.52$. 


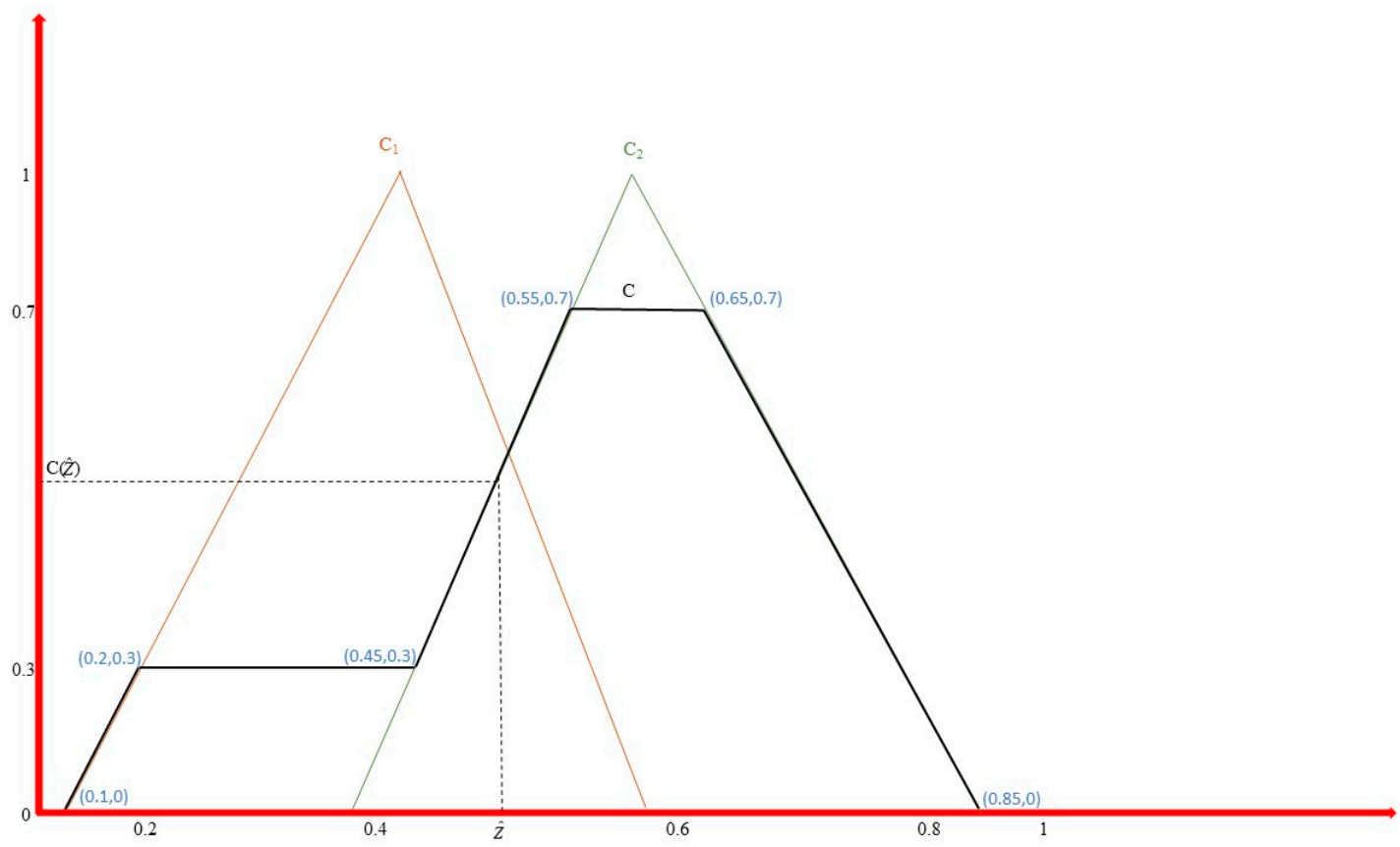

Figure 5. Results of the defuzzification process.

\subsection{Phase 4-Homogeneous Urban Context Creation}

In this phase, the area of study is partitioned into urban contexts. Each urban context is obtained by dissolving adjoining microzones belonging to the same urban class; then, the thematic map of the urban contexts of the area of study is created.

A weighted mean of the membership degree of the microzones forming an urban context is calculated, to extract the reliability of the urban context; the weight is given by the area of the microzone as the greater the surface of a microzone included in a context, the greater its impact on the reliability of the classification of the context.

\section{Application to an Area of Study}

We tested our model by applying it to an urban system in order to partition the area of study into urban contexts by considering the taxonomy of the urban area classes in Table 3.

\subsection{The Area of Study}

The area of study was given by the Municipality of Pozzuoli (Naples, Italy). The municipality of Pozzuoli comprises a multiplicity of urban area classes; it contains industrial areas, modern residential zones, a dense hold town, and highly uncultivated/wooded green areas. In Reference [27], historical land use, photogrammetric and airborne LiDAR data are used to detect buried landfill sites in the area of Campi Flegrei, which contains the municipality of Pozzuoli; this study showed that this area includes modifications to the landscape associated with urban development and quarrying activities. The presence of volcanic hills within the municipal area has allowed for urban development, mainly below them and towards the coastal areas. A survey of the seismic activities produced by the Campi Flegrei caldera in densely inhabited areas and the consequent risk for the population was carried out in Reference [28] and recently in Reference [29]. A study of all the different cultural resources present in the Municipality of Pozzuoli performed using GIS technologies is presented in Reference [30].

It is interesting to study how the various contexts in the municipality are distributed in relation to its different natural, social, and urban characteristics. We applied our model to obtain a partitioning of the municipality in these different contexts. 
Figure 6 shows the area of study; the microzones are outlined in yellow. The satellite base map was extracted using the ESRI satellite World Imagery database.

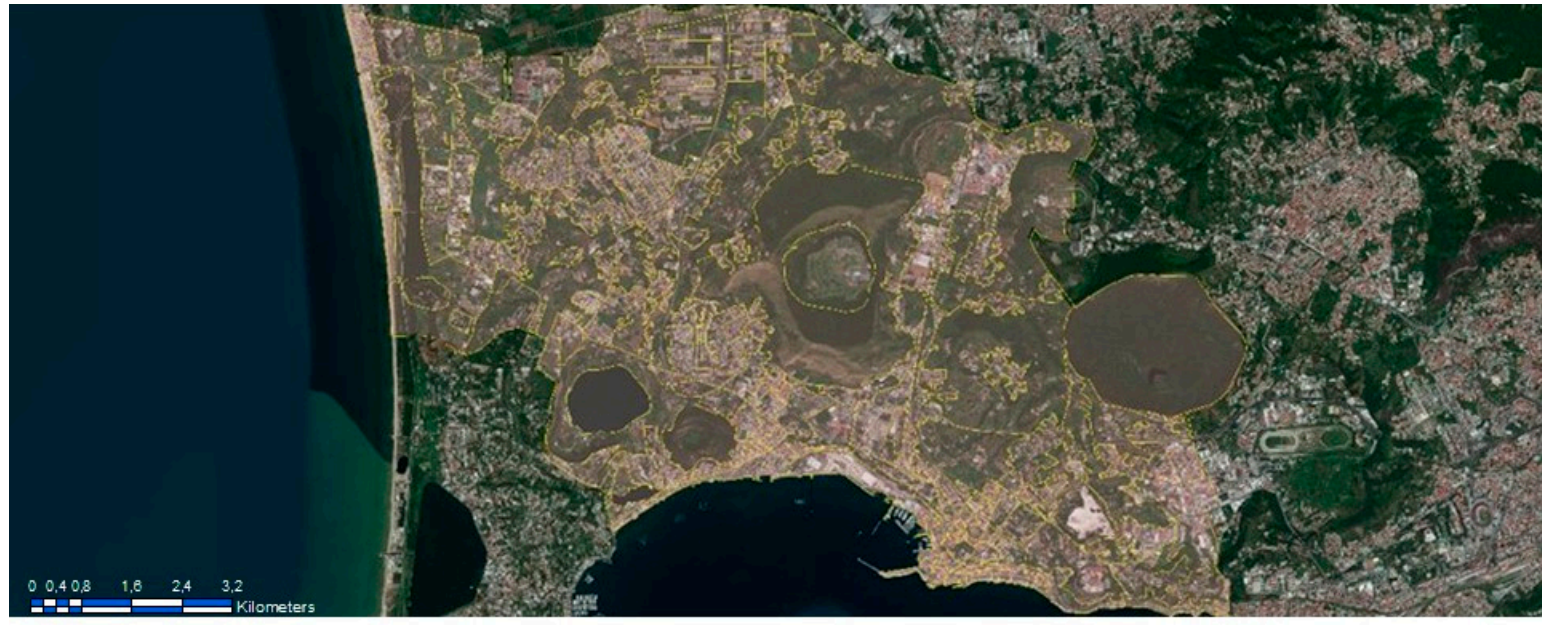

Figure 6. The microzones of the municipality of Pozzuoli.

\subsection{Spatial Data Sources}

The microzone dataset collected for the study was provided by the ISTAT, Italian National Statistical Institute, the Italian public research body that deals with censuses and surveys their social and economic characteristics.

The geo-topographic dataset used to extract the base theme of the municipality was the topographical database provided by the Campania Region in a 1:5000 scale, from which it was possible to extract information on buildings and their intended use, the presence of urban green, and the presence of infrastructure such as hospitals and schools. The area under study was a municipality bordering the seal; it was necessary to make some indicators for our set, to identify the coastal microzones.

The datasets needed to calculate the 14 indicators were extracted from four institutional data sources: the regional geo-topographic database in a scale of 1:5000, the census database provided with the last Italian census data per microzone, the aero-photogrammetric spatial database provided by the Municipality of Pozzuoli, and the free spatial database provided by the Open StreetMap community.

The datasets extracted were limited to the extension of the municipality of Pozzuoli.

All the data sources used in our tests are described in Table 6.

The polygonal census tracts dataset provided by the ISTAT institute was used as the base dataset to calculate the indicators; the census tracts corresponds to the microzones used in our model. The Municipality of Pozzuoli is partitioned into 283 microzones. For each microzone, we extracted the population dataset, composed of data concerning various sections of residents, such as the number of residents in a specific age range, and the building dataset composed of data related to the number of buildings and dwellings with specific characteristics, such as the number of buildings built in a given period, the mean number of dwellings in each residential building, etc.

The polygonal building theme was acquired from the 2011 geo-topographic database in a scale of 1:5000, distributed by the Campania Region in an Italian National geo-topographic structure following the InSpire GeoUML data model [31,32].

Other datasets concerning streets, infrastructures, and schools were extracted from the aero-photogrammetric municipality data in a scale of 1:4000, provided by the municipality of Pozzuoli and the OpenStreetMap community spatial database.

All the datasets were converted inti the plane coordinate system UTM WGS84 zone 33 N. The same data layers provided by different data sources were normalized and integrated. 
Table 6. Data sources and datasets used in the tests.

\begin{tabular}{|c|c|}
\hline \multicolumn{2}{|r|}{ Geo-Topographic Datasets } \\
\hline Institution & Campania Region \\
\hline Data Source & $\begin{array}{l}\text { Municipality of Pozzuoli-2012 Geo-Topographic Database in a scale of 1:5000, } \\
\text { coordinate system UTM WGS84 zone } 33 \text { N, plane coordinates. }\end{array}$ \\
\hline Datasets & $\begin{array}{l}\text { Industrial and residential buildings } \\
\text { Schools } \\
\text { Urban streets } \\
\text { Urban green areas } \\
\text { Woodlands and barred areas } \\
\text { Transport facilities } \\
\text { Hospitals } \\
\text { Sports facilities }\end{array}$ \\
\hline Institution & ISTAT-Italian National Institute of Statistics \\
\hline Data Source & $\begin{array}{l}2011 \text { Census database-Socio-Demographic Database per census tract in a scale of } \\
\text { 1:10,000, coordinate system UTM WGS84 zone } 32 \mathrm{~N} \text {, plane coordinates. } \\
\text { Website: https: / / www.istat.it/it/archivio/104317. }\end{array}$ \\
\hline Datasets & $\begin{array}{l}\text { Census tracts } \\
\text { Population dataset } \\
\text { Building and dwelling dataset }\end{array}$ \\
\hline Institution & Municipality of Pozzuoli \\
\hline Data Source & $\begin{array}{l}\text { Municipality spatial database, coordinate system UTM WGS84 zone } 33 \mathrm{~N} \text {, } \\
\text { scale 1:4000, coordinate system UTM WGS84 zone } 33 \mathrm{~N} \text {, plane coordinates. }\end{array}$ \\
\hline Datasets & $\begin{array}{l}\text { Municipality Ortho Images } \\
\text { Road network, railway network }\end{array}$ \\
\hline Institution & OpenStreetMap (OSM) community \\
\hline Data Source & $\begin{array}{l}\text { OpenStreetMap spatial database, coordinate system UTM WGS84 zone } 32 \mathrm{~N} \text {, } \\
\text { coordinate system UTM WGS } 84 \text { zone } 33 \mathrm{~N} \text {, plane coordinates. } \\
\text { Website: http:/ / download.geofabrik.de/osm-data }\end{array}$ \\
\hline Datasets & $\begin{array}{l}\text { Road network } \\
\text { Schools } \\
\text { Transport facilities } \\
\text { Bus and railway stops }\end{array}$ \\
\hline
\end{tabular}

\section{Test Results}

We tested our framework on a Pentium I7 dual core platform using the tool GIS ESRI ArcGIS 10.5; all the spatial analysis processes were implemented as functions in the tool GIS; and the fuzzy inference system was implemented in $\mathrm{C}++$ language and incapsulated in the tool GIS.

In order to calculate the indicators needed to test our model, a set of spatial operators, such as spatial intersects and spatial joins, was used to calculate the indicators assigned to the microzones starting from the data acquired from the various spatial datasets. Then, the processes applied to extract the indicators were synthetized.

To calculate the indicators $\mathrm{I}_{1}$ and $\mathrm{I}_{2}$, the polygonal building dataset was partitioned into residential and industrial buildings in order to extract, respectively, the area covered by residential and industrial buildings per microzone.

Indicator $\mathrm{I}_{3}$, given by the mean square meters of green areas per resident, was calculated by selecting the urban green areas and calculating the sum of urban green areas covering any microzone. Finally, this area was divided by the number of residents in the microzone.

Indicator $\mathrm{I}_{4}$ was calculated by dividing the sum of green areas in the microzone by the area of the microzone. 
To calculate the indicators $I_{5}$, the district urban roads were selected from the road network layer and the sum of the lengths of the selected arcs falling in each microzone was calculated; finally, this value was divided by the sum of the length of all the road arcs falling in the microzone. Indicator $\mathrm{I}_{6}$ was calculated by selecting the district urban roads with a width of less than $7 \mathrm{~m}$ and dividing the sum of the selected arcs fallings in any microzone by the sum of the district urban road arcs falling in the microzone.

Indicator $\mathrm{I}_{7}$ was calculated by dividing the number of residents in any microzone by the area of the microzone in square kilometers.

To calculate the indicators $\mathrm{I}_{8}, \mathrm{I}_{9}$, and $\mathrm{I}_{10}$, the building and dwelling census dataset was used, extracting, for each microzone, respectively, the number of residential buildings built before 1945, the number of dwellings with at least one resident, and the number of residential buildings with at least 16 dwellings, and dividing them, respectively, by the number of residential buildings, the number of dwellings, and the number of residential buildings in the microzone.

The II level indicators $\mathrm{I}_{11 \mathrm{a}}, \mathrm{I}_{11 b}$ and $\mathrm{I}_{11 \mathrm{c}}$ were calculated by extracting from the point school layer, respectively, the primary, low secondary, and secondary schools, and constructing circular buffer areas with a radius of $500 \mathrm{~m}$ centered in any school. Then, for any type of school, the area of the microzone covered by the calculated buffer areas was extracted and divided by the area of the microzone.

The II level indicators $\mathrm{I}_{12 \mathrm{a}}$ and $\mathrm{I}_{12 \mathrm{~b}}$ were calculated by extracting from the point transport facility layers, respectively, the bus stops and the railway stops, and constructing circular buffer areas with a radius of 100 and 300, respectively, centered in any stop. Then, for any type of stop, the area of the microzone covered by the buffer areas calculated was extracted and divided by the area of the microzone.

The II level indicators $\mathrm{I}_{13}$ and $\mathrm{I}_{13 \mathrm{~b}}$ were calculated by selecting, respectively, microzones including coastal areas and those containing a maritime terminal.

The II level indicators $\mathrm{I}_{14 \mathrm{a}}$ and $\mathrm{I}_{14 \mathrm{~b}}$ were calculated by extracting, respectively, the polygon hospital and sports facility layers and selecting the microzones including the selected elements.

For brevity, we showed the thematic maps obtained for the indicators $\mathrm{I}_{2}$ (Figure 7) and $\mathrm{I}_{4}$ (Figure 8) in which an equal interval classification method of the indicator is applied.

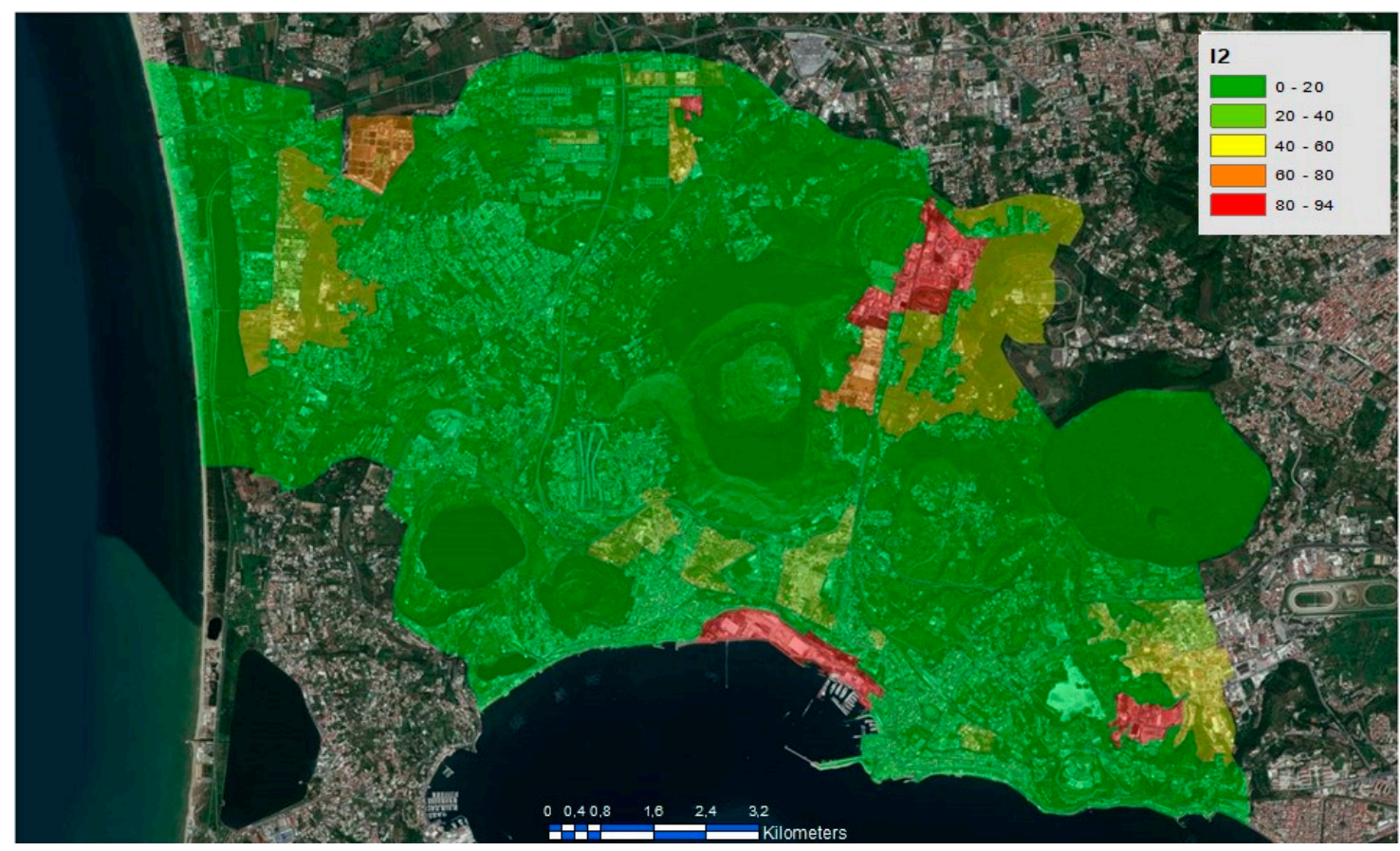

Figure 7. Thematic map of the indicator $\mathrm{I}_{2}$-Percent of industrial areas with respect to total built areas. 


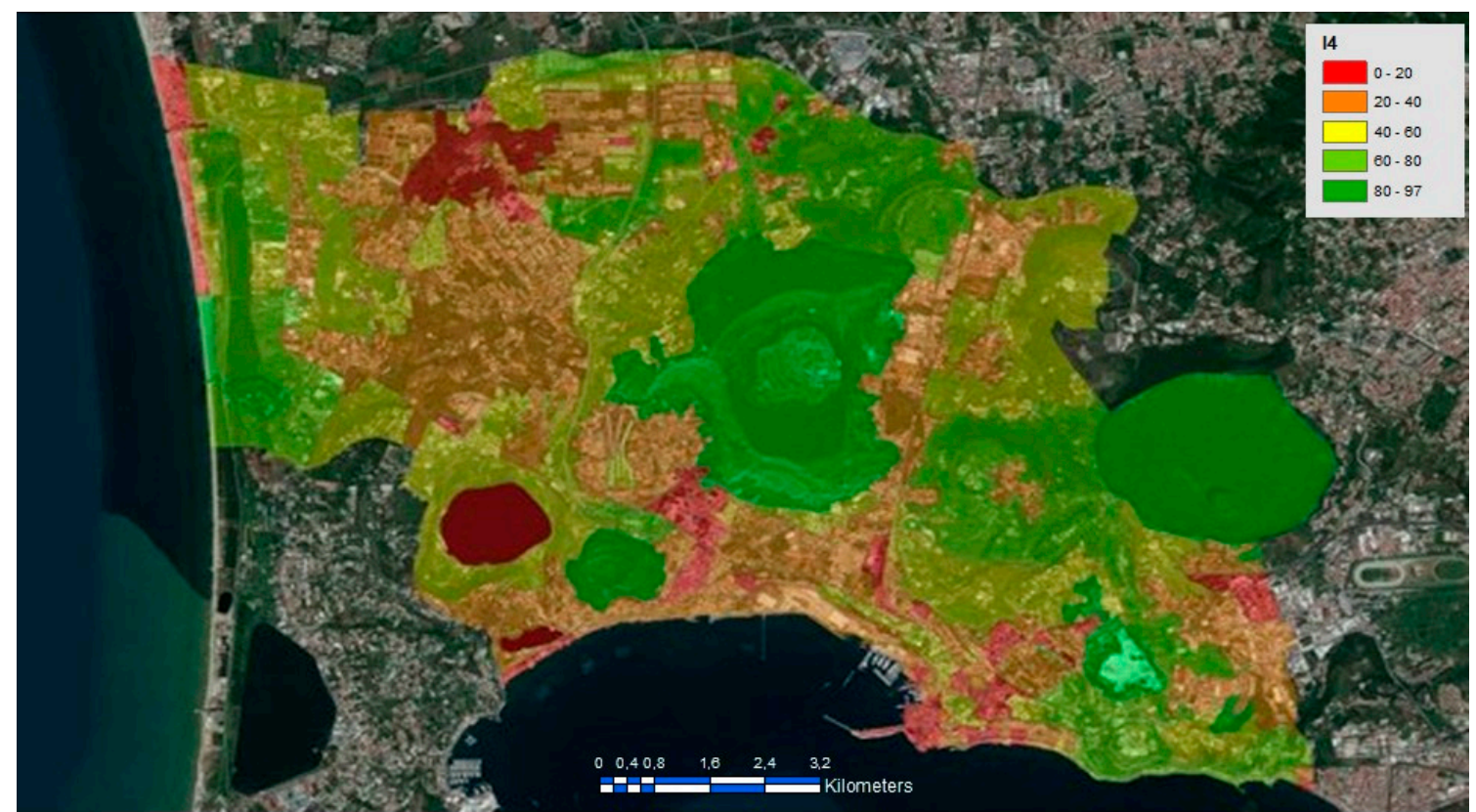

Figure 8. Thematic map of the indicator $\mathrm{I}_{4}$-Percent of green areas with respect to the area of the microzone.

After calculating the crisp values of the indicators, we applied the fuzzification process, executing the fuzzifier component of the fuzzy rule system.

Figures 9 and 10 present two thematic maps of, respectively, the indicators $\mathrm{I}_{2}$ and $\mathrm{I}_{4}$, in which each microzone is assigned the label of the fuzzy set to which the microzone belongs with the highest membership degree.

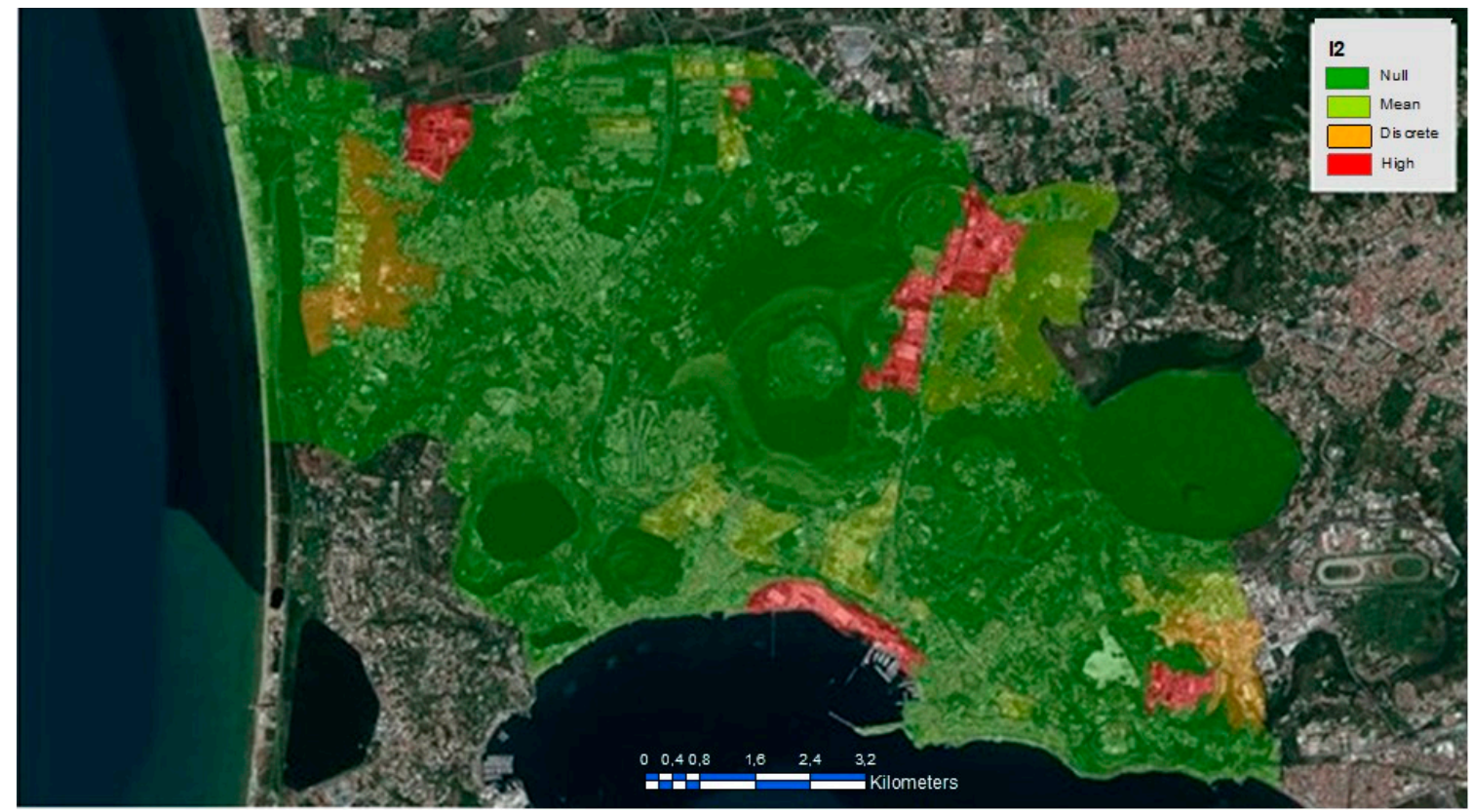

Figure 9. Thematic map of the indicator $I_{2}$ in which each microzone is classified by assigning it the label of the fuzzy sets to which it belongs with the highest membership degree. 


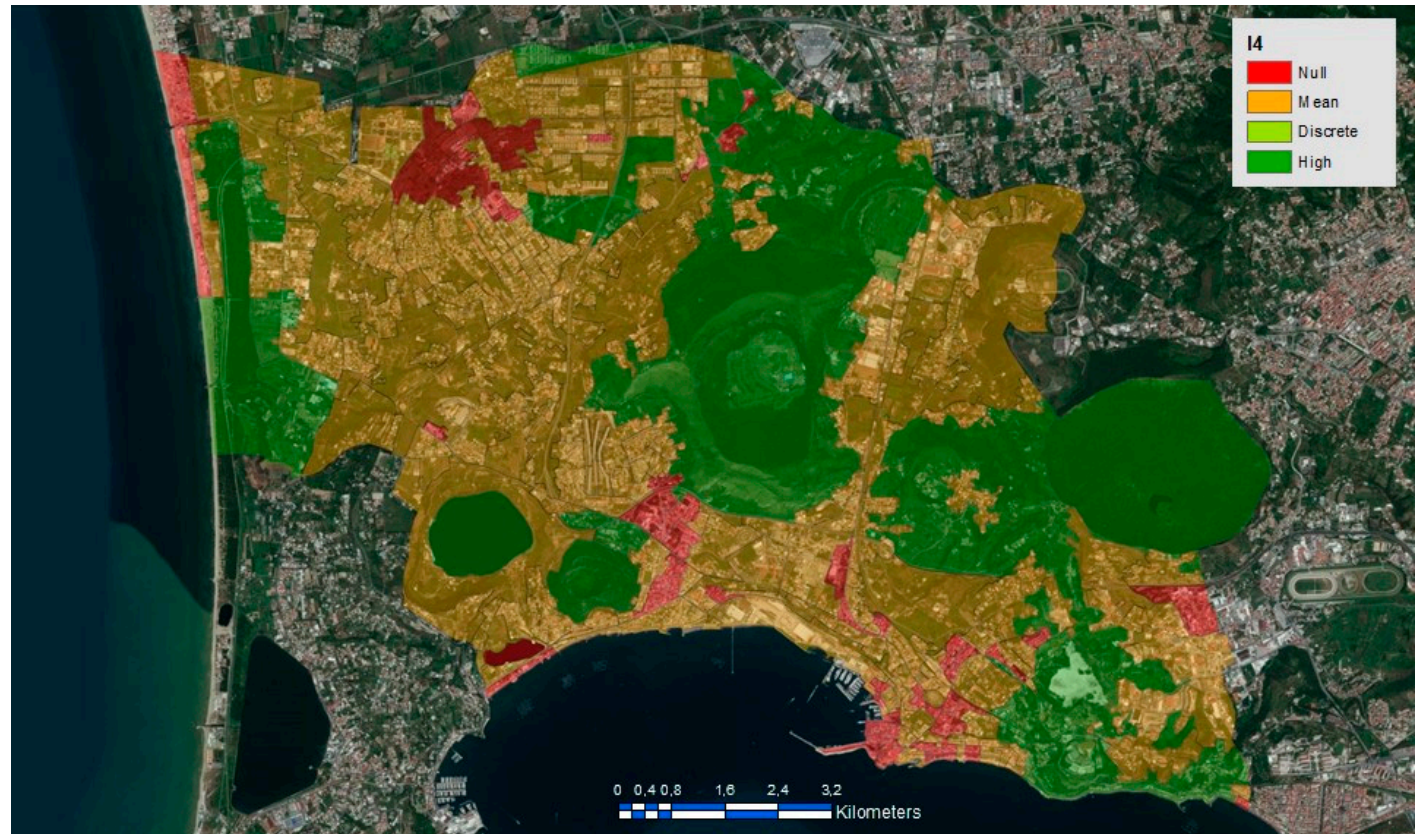

Figure 10. Thematic map of the indicator $\mathrm{I}_{4}$ in which each microzone is classified by assigning it the label of the fuzzy sets to which it belongs with the highest membership degree.

The two maps in Figures 9 and 10 were obtained after the fuzzification process and highlight the microzones characterized by the indicator. In Figure 9, the microzones classified as High (in red) are characterized by a strong presence of industrial areas. In Figure 10, the microzones classified as High (in dark green) are largely covered by urban or overgrown green.

After the fuzzification process, the fuzzy inference engine component was initiated; a set of about 100 fuzzy rules created by the domain experts was used. Finally, the defuzzification process was executed and the appropriated urban area class was assigned to each microzone.

The thematic map in Figure 11 show the classification results. In this map, the urban area classification of the microzone is shown.

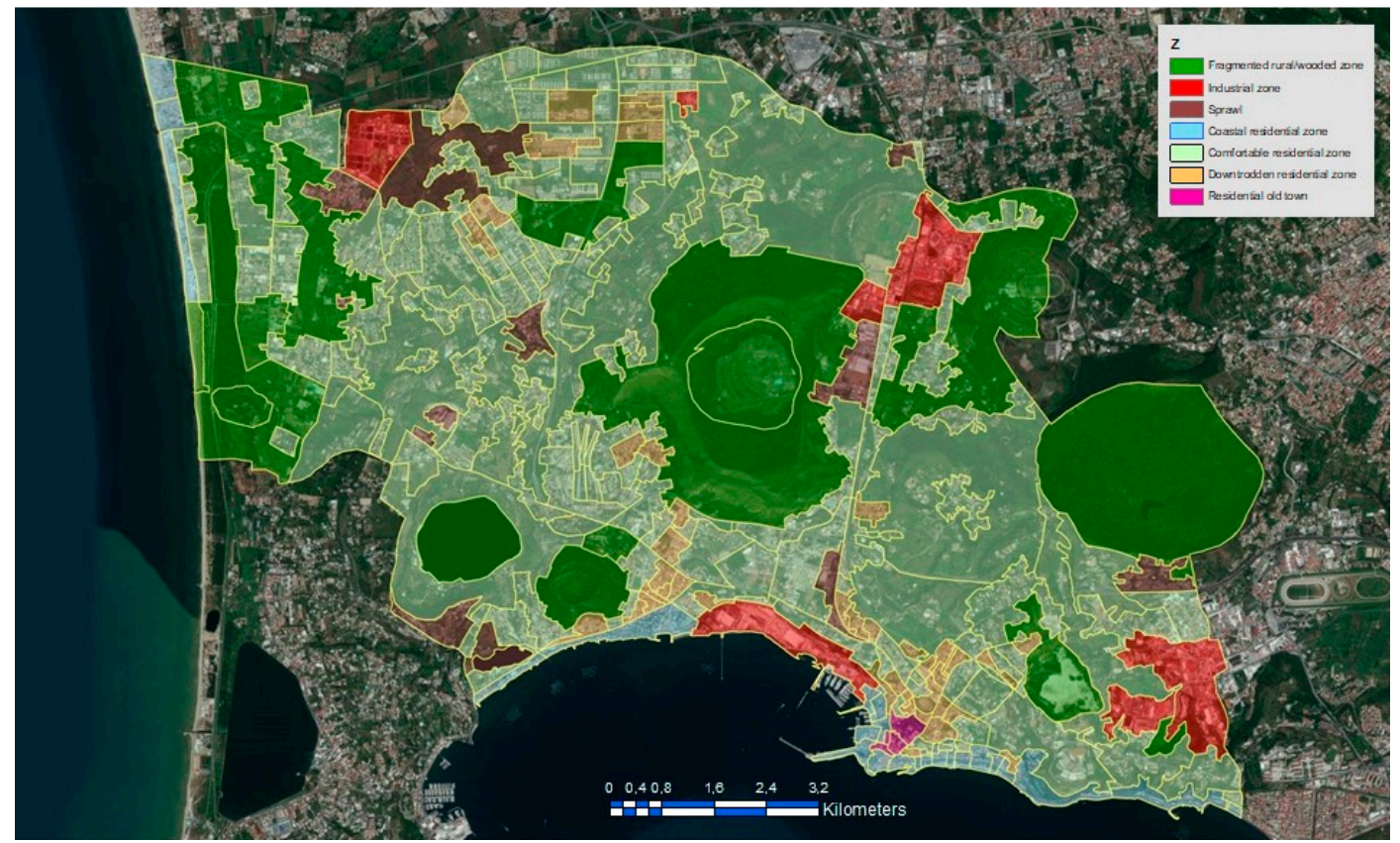

Figure 11. Thematic map of the microzones classified by urban area. 
In order to evaluate the performance of the classification, we compared the results with the supervised urban area classification of the microzones performed by the experts. For each class, we calculated the accuracy, precision, and recall (or sensitivity) indexes. This calculus was performed by extracting, from the confusion matrix, the TP, TN, FP, and FN parameters, where:

- $\quad$ TP (True Positive) is the number of microzones correctly assigned to the class;

- $\quad$ TN (True Negative) is the number of microzones correctly not assigned to the class;

- $\quad$ FP (False Positive) is the number of microzones wrongly assigned to the class;

- $\quad$ FN (False Negative) is the number of microzones wrongly not assigned to the class.

The three indexes are given by:

$$
\begin{aligned}
& \text { accuracy }=\frac{\mathrm{TP}+\mathrm{TN}}{\mathrm{TP}+\mathrm{TN}+\mathrm{FP}+\mathrm{FN}} \times 100 \\
& \text { precision }=\frac{\mathrm{TP}}{\mathrm{TP}+\mathrm{FP}} \times 100 \\
& \text { recall }=\frac{\mathrm{TP}}{\mathrm{TP}+\mathrm{FN}} \times 100
\end{aligned}
$$

Table 7 show the classification results; the three indexes were calculated for any class.

Table 7. Classification results obtained by comparing the urban area classifications of the microzones obtained by applying our method with the supervised classification performed by the experts.

\begin{tabular}{cccc}
\hline Urban Area Class & Accuracy & Precision & Recall \\
\hline Fragmented rural/wooded zone & $99.29 \%$ & $100.00 \%$ & $88.89 \%$ \\
Industrial zone & $100.00 \%$ & $100.00 \%$ & $100.00 \%$ \\
Sprawl & $100.00 \%$ & $84.62 \%$ & $100.00 \%$ \\
Coastal residential zone & $100.00 \%$ & $100.00 \%$ & $100.00 \%$ \\
Comfortable residential zone & $100.00 \%$ & $100.00 \%$ & $100.00 \%$ \\
Downtrodden residential zone & $100.00 \%$ & $100.00 \%$ & $100.00 \%$ \\
Residential old town & $100.00 \%$ & $100.00 \%$ & $100.00 \%$ \\
\hline
\end{tabular}

These results show that the classification of the microzones obtained by applying our model is almost similar to the supervised one attributed by the experts. The only deviations are present for the indexes Accuracy and Recall in the classes Fragmented rural/wooded zone and Sprawl; two of the 18 microzones classified by the experts as Fragmented rural/wooded zone by using our model are classified as Sprawl.

Finally, adjoining microzones belonging to the same class were dissolved, forming urban contexts.

The Municipality of Pozzuoli is partitioned into 60 urban contexts, as shown in the map in Figure 12.

The only urban context classified as Residential old town (in magenta) is an area that includes the historical center of Pozzuoli. The urban contexts classified as Coastal residential zone (in light blue) are residential coastal areas. The other coastal areas are, respectively, the maritime industrial area, classified as Industrial zone, and an area given by a maritime non-residential microzone, classified as Fragmented rural/wooded zone since it is not a residential zone and a high percentage of the zone is covered by vegetation. All the contexts classified as Industrial zone (in red) are areas where most of the buildings are industrial buildings or warehouses. The contexts classified as Downtrodden residential zone (in orange) are residential areas with a high density of residential housings and with a high population density. The other average residential contexts are classified as Comfortable residential zone (in light green); in these zones, the population density and the number of dwellings per residential building are not high; in addition, these zones are mostly covered by transportation services and schools and contain public green areas. The contexts classified as Sprawl (in brown) are areas where the density of residential buildings is sparse; they are probably urban agglomerations in recent, slow, and unplanned expansion. Finally, the contexts classified as Fragmented rural/wooded zone (in green) are areas predominantly or completely covered with vegetation. 


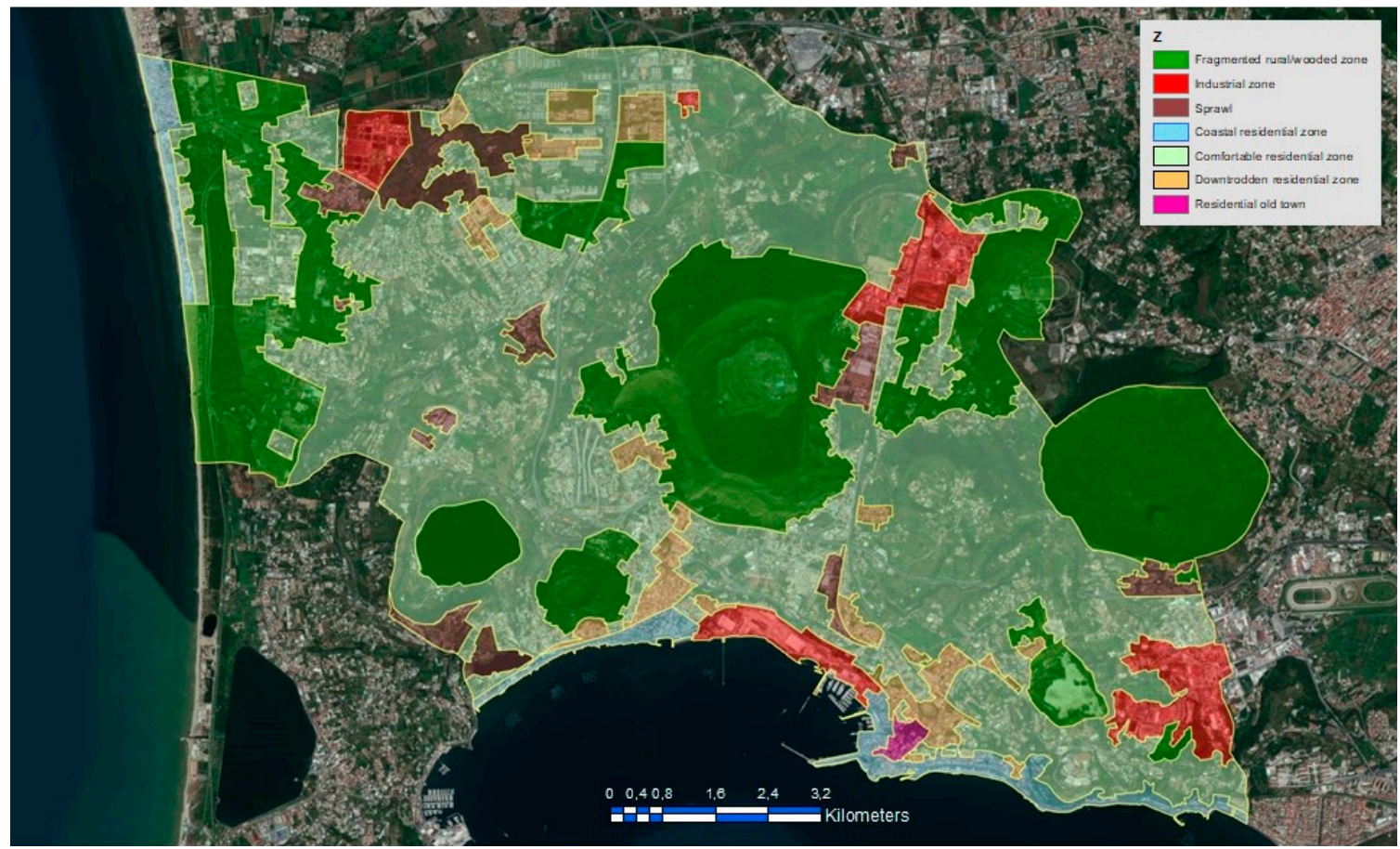

Figure 12. Thematic map of the urban contexts.

In Figure 13, a thematic map with the reliability of the results is presented. The reliability is calculated as a weighted average of the membership degree to the urban area class of the microzones included in the context where the weight is given by the area of the microzone.

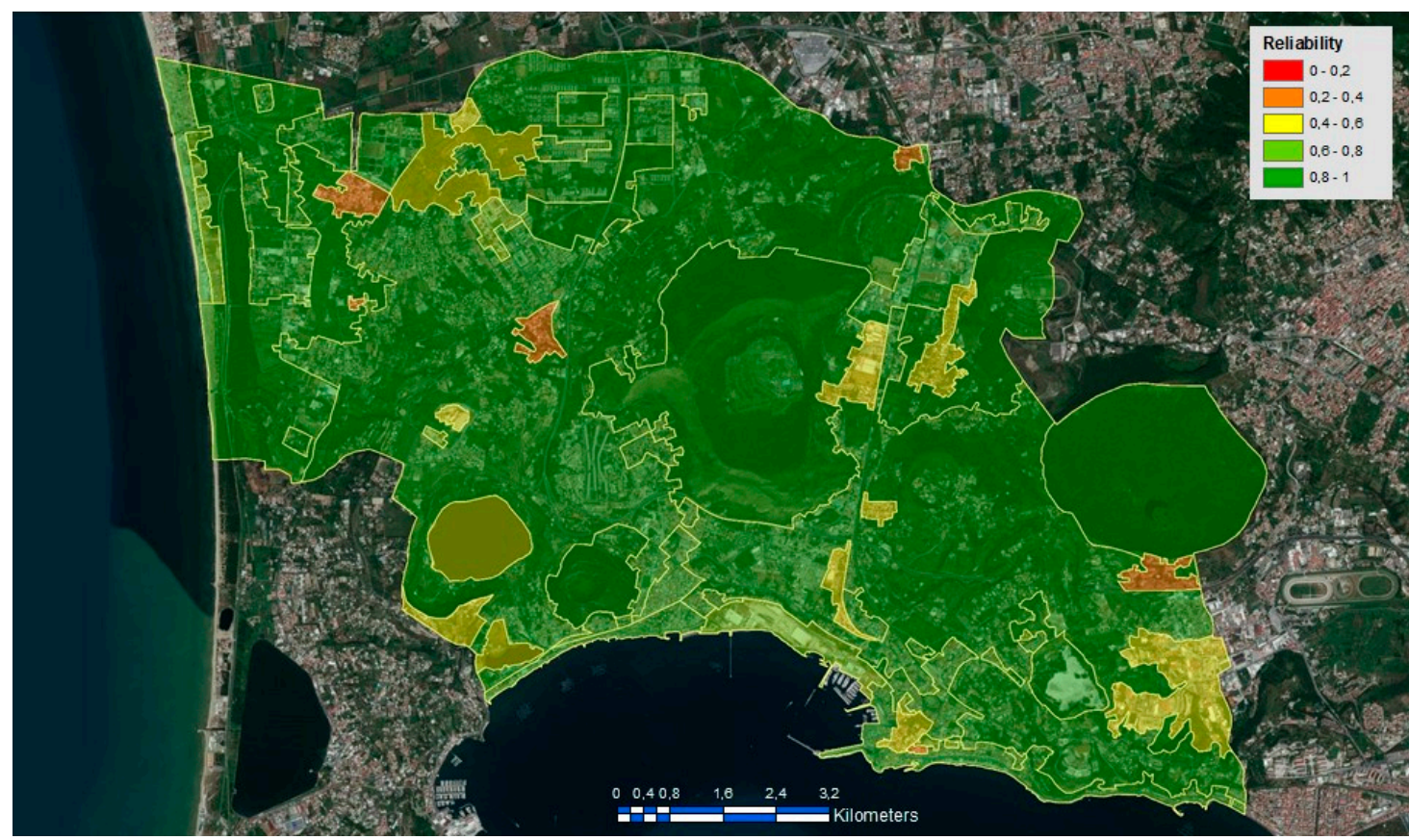

Figure 13. Thematic map of the reliability of the urban contexts.

There are four contexts with a low reliability, in the range of 0.2-0.4: three of these contexts are classified as Sprawl and the last as Downtrodden residential zone. In all these contexts, microzones with a not high degree of membership to their urban area class, meanly under the value of 0.4 , are included. 
These results suggest the need for a finer classification of urban areas in order to improve the reliability of urban contexts with a low reliability. In fact, in microzones classified as a specified urban area with a low membership degree, there are probably different types of urban areas; a finer classification could also take into account classes of urban areas to which microzones belong with a slightly lower degree of membership. For example, the context with low reliability classified as Downtrodden residential zone is given by a microzone classified as Downtrodden residential zone with a membership degree of 0.36 and belonging to the class Industrial zone with a membership degree of 0.31; this microzone included a densely populated residential area and a non-residential area with industrial premises; a finer classification of this microzone could consider both these classes in order to characterize the type of urban area that it represents in greater detail.

\section{Final Considerations}

We have presented a new model based on a Mamdani fuzzy rule system to partition an urban system into homogeneous urban contexts. We implemented our model using a GIS platform and constructed the urban contexts by initially considering the urban system partitioned into microzones. A set of indicators was defined to characterize the urban areas; these indicators were fuzzified and used as variables in a fuzzy rule set used to classify the microzones; the urban contexts were obtained by dissolving adjoining microzones belonging to the same urban area class. We assessed the reliability of our classification, assigning each urban context the weighted average of the membership degree of the microzones within in it, where the weight was given by the area of the microzone.

We tested our model by applying it to the Municipality of Pozzuoli (Italy) in order to partition the municipality into contexts classified based on the type of residential or rural area.

A comparison of the results with the results of a supervised classification obtained by experts showed that our model had a high classification performance in terms of accuracy, precision, and recall. The results show that the contexts where reliability is low include microzones in which zones with different characteristics are present. Our approach could be a valid support for decision makers in analyzing how the urban fabric is characterized and how it is spatially distributed in areas with complex characteristics for the purposes of proper management and planning.

In the future, we intend to improve this model in order to obtain a finer partition of the urban system by considering all the most relevant classes of urban areas characterizing microzones.

Author Contributions: The two authors participated equally in writing all the sections of this article and in the research activities necessary for the design, implementation, and testing of the proposed model.

Funding: This research received no external funding.

Acknowledgments: We would like to thank the references of Office 5: “Urban Planning-Government of the Territory" of the Municipality of Pozzuoli, and its manager, Arch. Agostino Di Lorenzo, for their support and the provision of all the data available at the Municipality used in the research.

Conflicts of Interest: The authors declare no conflict of interest.

\section{References}

1. Sheeren, D.; Quirin, A.; Puissant, A.; Gançarski, P.; Weber, C. Discovering rules with genetic algorithms to classify urban remotely sensed data. In Proceedings of the 2006 IEEE International Symposium on Geoscience and Remote Sensing, Denver, CO, USA, 31 July-4 August 2006; pp. 3902-3905. [CrossRef]

2. Forestier, G.; Wemmert, C.; Puissant, A. Coastal image interpretation using background knowledge and semantics. Comput. Geosci. 2013, 54, 89-96. [CrossRef]

3. Leichtle, T.; Geiß, C.; Wurm, M.; Lakes, T.; Taubenböck, H. Unsupervised change detection in VHR remote sensing imagery-An object-based clustering approach in a dynamic urban environment. Int. J. Appl. Earth Observ. Geoinf. 2013, 2017, 15-27. [CrossRef]

4. Chen, Y.; Su, W.; Li, J.; Sung, Z. Hierarchical object-oriented classification using very high-resolution imagery and LIDAR data over urban areas. Adv. Space Res. 2009, 43, 1101-1110. [CrossRef] 
5. Gu, Y.; Wang, Q.; Jia, X.; Benediktsson, J.A. A Novel MKL Model of Integrating LiDAR Data and MSI for Urban Area Classification. IEEE Trans. Geosci. Remote Sens. 2015, 53, 5312-5326. [CrossRef]

6. Yan, W.Y.; Shaker, A.; El-Ashmawy, N. Urban land cover classification using airborne LiDAR data: A review. Remote Sens. Environ. 2015, 158, 295-310. [CrossRef]

7. Rikalović, A.; Antunes Soares, G.; Ignjatić, J. Spatial analysis of logistics center location: A comprehensive approach. Decis. Mak. Appl. Manag. Eng. 2018, 1, 38-50. [CrossRef]

8. Preradović, L.; Đajić, V.; Jakovljević, G. Gender and age structure as risk factors of carotid artery stenosis and specific themes areas of cartography. Decis. Mak. Appl. Manag. Eng. 2018, 1, 111-120. [CrossRef]

9. Pamučar, D.; Gigović, L.; Ćirović, G.; Regodić, M. Transport spatial model for the definition of green routes for city logistics centers. Environ. Impact Assess. Rev. 2016, 56, 72-87. [CrossRef]

10. Pamučar, D.; Gigović, L.; Bajić, Z.; Janošević, M. Location Selection for Wind Farms Using GIS Multi-Criteria Hybrid Model: An Approach Based on Fuzzy and Rough Numbers. Sustainability 2017, 9, 1315. [CrossRef]

11. Di Martino, F.; Loia, V.; Sessa, S. A fuzzy-based tool for modelization and analysis of the vulnerability of aquifers: A case study. Int. J. Approx. Reason. 2005, 38, 99-111. [CrossRef]

12. Mennis, J.; Liu, J.W. Mining Association Rules in Spatio-Temporal Data: An Analysis of Urban Socioeconomic and Land Cover Change. Remote Sens. Environ. 2005, 9, 5-17. [CrossRef]

13. Bernábe, M.B.L.; Duque, J.C.; Ramirez, J.R.; Osorio, M.A.L. Classification over Geographical Zones: A Combinatorial O ptimization Approach to the Regional Partitioning Problem. In Proceedings of the 18th International Conference on Electronics, Communications and Computers, Puebla, Mexico, 3-5 March 2008; pp. 70-74. [CrossRef]

14. Di Martino, F.; Sessa, S. Spatial analysis and fuzzy relation equations. Adv. Fuzzy Syst. 2011, 2011, 429498. [CrossRef]

15. Arns Steiner, M.T.; Datta, D.; Steiner Neto, P.J.; Scarpin, C.T.; Figueira, J.R. Multi-objective optimization in partitioning the healthcare system of Parana State in Brazil. Omega 2015, 52, 53-64. [CrossRef]

16. Mamdani, E.H.; Assilian, S. An experiment in linguistic synthesis with a fuzzy logic controller. Int. J. Man-Mach. Stud. 1975, 7, 1-13. [CrossRef]

17. Mamdani, E.H. Application of fuzzy logic to approximate reasoning using linguistic synthesis. IEEE Trans. Comput. 1977, 26, 1182-1191. [CrossRef]

18. Lukovac, V.; Pamučar, D.; Popović, M.; Đorović, B. Portfolio model for analyzing human resources: An approach based on neuro-fuzzy modeling and the simulated annealing algorithm. Expert Syst. Appl. 2017, 90, 318-331. [CrossRef]

19. Pamučar, D.; Vasin, L.; Atanasković, P.; Milicic, M. Planning the City Logistics Terminal Location by Applying the Green p-Median Model and Type-2 Neurofuzzy Network. Comput. Intell. Neurosci. 2016, 2. [CrossRef]

20. Pamučar, D.; Atanasković, P.; Milicic, M. Modeling of fuzzy logic system for investment management in the railway infrastructure. Teh. Vjesn. 2015, 22, 1185-1192. [CrossRef]

21. Tarigan, P.; Simurat, S. Implementation of A Mamdani Fuzzy Logic Controller for Building Automation Using Electronic Control Based on AT89S51. In Proceedings of the 2015 International Conference on Technology, Informatics, Management, Engineering \& Environment (TIME-E), Samosir, Indonesia, 7-9 September 2015; pp. 87-92. [CrossRef]

22. Mesran, M.; Syahrizal, M.; Suginam, S.; Kurniasih, N.; Gs, A.D. Expert System for Disease Risk Based on Lifestyle with Fuzzy Mamdani. Int. J. Eng. Technol. 2018, 7, 88-91. [CrossRef]

23. Li, X.; Dan, G. Behavior-based Mamdani fuzzy controller for mobile robot wall-following. In Proceedings of the 2015 International Conference on Control, Automation and Robotics, Singapore, 20-22 May 2015; pp. 78-81. [CrossRef]

24. Zareiforoush, H.; Minaei, S.; Alizadeh, M.R.; Banakar, A. A hybrid intelligent approach based on computer vision and fuzzy logic for quality measurement of milled rice. Measurement 2015, 66, 26-34. [CrossRef]

25. Hasan, R.; Monir, S.M.G. Fruit maturity estimation based on fuzzy classification. In Proceedings of the 2017 IEEE International Conference on Signal and Image Processing Applications (ICSIPA), Kuching, Malaysia, 12-14 September 2017; pp. 27-32. [CrossRef]

26. Mahalakshmi, P.; Ganesan, K. Mamdani fuzzy rule-based model to classify sites for aquaculture development. Indian J. Fish. 2015, 62, 110-115. 
27. Esposito, G.; Matano, F.; Sacchi, M. Detection and Geometrical Characterization of a Buried Landfill Site by Integrating Land Use Historical Analysis, Digital Photogrammetry and Airborne Lidar Data. Geosciences 2018, 8, 348. [CrossRef]

28. Judenherc, S.; Zollo, A. The Bay of Naples (Southern Italy): Constraints on the volcanic structures inferred from a dense seismic survey. J. Geophys. Res. Atmos. 2004, 109. [CrossRef]

29. Petrosino, S.; Cusano, P.; Madonia, P. Tidal and hydrological periodicities of seismicity reveal new risk scenarios at Campi Flegrei caldera. Sci. Rep. 2018, 8, 13808. [CrossRef] [PubMed]

30. Gerundo, C.; Adad, G.N. Promoting Cultural Resources Integration Using GIS. The Case Study of Pozzuoli. In New Metropolitan Perspectives. ISHT 2018. Smart Innovation, Systems and Technologies; Calabrò, F., Della Spina, L., Bevilacqua, C., Eds.; Springer: Cham, Switzerland, 2018; Volume 100, pp. 182-188.

31. Belussi, A.; Negri, M.; Pelagatti, G. GeoUML: A Geographic Conceptual Model Defined Through Specialization of Iso Tc211 Standards. In Proceedings of the 10th EC GI \& GIS Workshop, ESDI State of the Art, Warsaw, Poland, 23-25 June 2004.

32. Pelagatti, G.; Belussi, A.; Negri, M. GeoUML Methodology e Tools an Overview. Spatial DB Group Politecnico di Milano-Comitato di Progetto e Struttura Tecnica di Supporto CISISCPSG. 2011. Available online: http:/ / geo.spatialdbgroup.polimi.it/en/documents/ (accessed on 25 November 2018).

(c) 2018 by the authors. Licensee MDPI, Basel, Switzerland. This article is an open access article distributed under the terms and conditions of the Creative Commons Attribution (CC BY) license (http:/ / creativecommons.org/licenses/by/4.0/). 